University of Rhode Island

DigitalCommons@URI

Open Access Dissertations

2009

\title{
A Stereotype Threat Intervention That Examines Causal Attributions, Self-Efficacy, and Perceived Faculty Support
}

Megan Frost

University of Rhode Island

Follow this and additional works at: https://digitalcommons.uri.edu/oa_diss

\section{Recommended Citation}

Frost, Megan, "A Stereotype Threat Intervention That Examines Causal Attributions, Self-Efficacy, and Perceived Faculty Support" (2009). Open Access Dissertations. Paper 929.

https://digitalcommons.uri.edu/oa_diss/929

This Dissertation is brought to you for free and open access by DigitalCommons@URI. It has been accepted for inclusion in Open Access Dissertations by an authorized administrator of DigitalCommons@URI. For more information, please contact digitalcommons-group@uri.edu. 
A STEREOTYPE THREAT INTERVENTION THAT EXAMINES

CAUSAL ATTRIBUTIONS, SELF-EFFICACY,

AND PERCEIVED FACULTY SUPPORT

BY

MEGAN FROST

A DISSERTATION SUBMITTED IN PARTIAL FULFILLMENT OF THE

REQUIREMENTS FOR THE DEGREE OF

DOCTOR OF PHILOSOPHY

IN PSYCHOLOGY

UNIVERSITY OF RHODE ISLAND

2009 


\begin{abstract}
\end{abstract}
Women underperform on math tasks in comparison to men when they are in a situation that is high in stereotype threat. Stereotype threat intervention research has found several methods for improving performance, such as allowing the female participants to attribute potential failure to an external source. This study replicated the results of a teaching intervention study that consisted of informing participants about stereotype threat, and asked that they attribute any performance-related anxiety to stereotype threat. All study participants were women. In order to make the stereotype threat message more salient, participants learned about the concept and theory by watching a video of Claude Steele discussing his research. The study additionally examined the attributions made for performance on the math test using the Causal Dimension Scale II. All participants were debriefed at the end of the study. The results revealed no significant differences were found between the math test performances of the participants who were taught about stereotype threat and those who were not, $F$ $(7,91)=.45, p=.87$, partial eta squared $=.03$, Wilk's Lambda $=.97$. The study did not show significant differences between groups on the Causal Dimension Scale II, a scale which measures attributions made for success or failure on a task, $F(4,95)=.40, \mathrm{p}=.30$, partial eta squared $=.013$, Wilk's Lambda $=.99$. This study also looked at factors such as self-efficacy and perceived faculty support. Predictive relationships were examined by looking at treatment condition, selfefficacy, and perceived faculty support to see if these individual variables predict 
math test performance. Perceived faculty support did not predict math test scores, $F(1,98)=.10, \mathrm{p}=.90$, self-efficacy did not predict math test scores, $F(1,98)=$ $.11, p=.92$, and treatment condition did not predict math test performance, $F(1$, $98)=.21, p=.99$. This study also examined potential interaction effects between self-efficacy with perceived faculty support and also self-efficacy with internal attributions in order to examine if they predict math test performance. Results indicated that these factors were not predictive of performance on the math test. Interaction effects were not significant resulting in self-efficacy and perceived faculty support not interacting to predict math test performance, $F(3,96)=.09, \mathrm{p}$ $=.97$ and self-efficacy and internal attributions did not interact to predict math test performance, $F(3,96)=.268, \mathrm{p}=.849$. Finally, this study examined if participants were able to retain the central message associated with stereotype threat theory one week after completing the study. Results demonstrated that the majority of the participants were able to retain the message after completing the study, as participants in this group were able to obtain $77 \%$ of the questions correct. Future stereotype threat research may need to focus on examining interventions that buffer participants from stereotype threat effects and remain beneficial to the participant even after they have left the study. If we aim to end the disidentification of women within the domains of math and science, we need to examine effective interventions that potentially have long-term effects. 


\section{Acknowledgements}

I would like to express my great appreciation to Margaret Rogers. She was instrumental in assisting me to complete this research project. She was extremely helpful in providing me with constructive feedback, superior editing skills, a good sense of humor, and the motivation to follow this project through to the end. I would additionally like to thank my committee members Drs. Lisa Harlow, Faye Boudreaux-Bartels, and JoAnn Hammadou for their time and interest in this project.

I would also like to thank my family and friends for their support. Your belief in my ability to complete my doctorate helped me to believe in myself as well. 


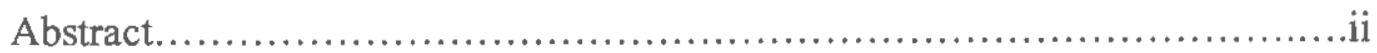

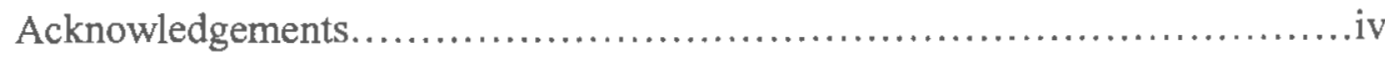

Table of Contents...........................................................

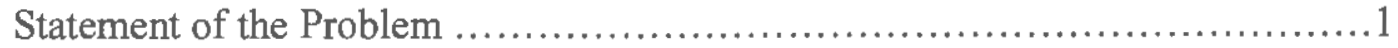

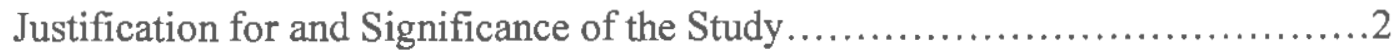

Direct and Indirect Stereotype Threat Activation Models.......................15

Studies Examining Why Stereotype Threat Effects Exist.....................20

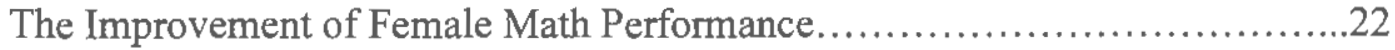

Effect of Making Attributions for Potential Failure............................26

Retention of Stereotype Threat Message ....................................33

Self-Efficacy and Academic Achievement................................... 34

Faculty Support of Females in Math and Science Fields......................37

Goals of the Current Study ..................................................40

Statement of Purpose....................................................41

Research Hypotheses.................................................42

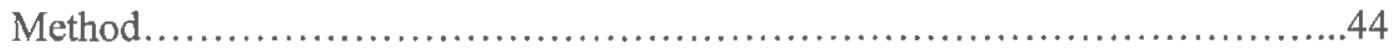

Participants.....................................................44

Measures/Instrumentation.........................................45

Math Test.................................................45

Causal Dimension Scale II.................................46 
General Self-Efficacy Scale ..................................47

Perceived Faculty Support Scale................................48

Demographic Survey........................................48

Procedures............................................................ 49

Data Analysis...................................................51

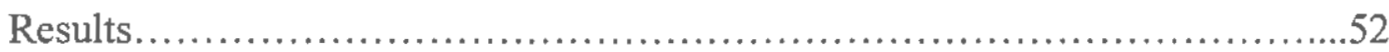

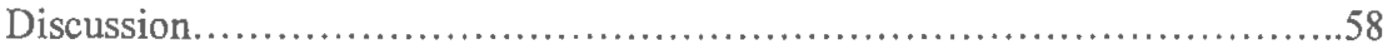

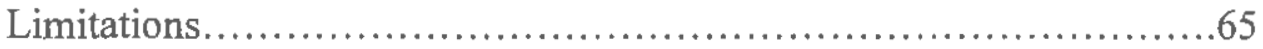

Future Research Directions.........................................66

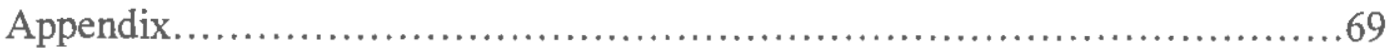

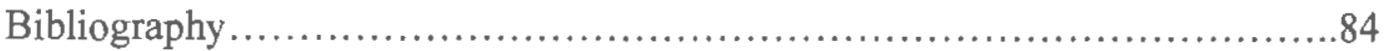




\section{Statement of the Problem}

There are far fewer women than men who choose to complete undergraduate and graduate degrees in a number of math and science-oriented fields (National Center for Education Statistics, [NCES] 2004). Stereotype threat research has demonstrated that females can experience performance deficits when they are reminded of negative stereotypes that exist regarding female performance in domains such as math (Ambady, Paik, Steele, Owen-Smith, \& Mitchell, 2003; Inzlicht \& Ben-Zeev, 2000; Johns, Schmader, \& Martens, 2005; Martens, Johns, Greenberg, \& Schimel, 2006). In order to examine how female performance can improve in stereotype threat situations, this intervention study examined a method to improve female performance when in stereotype threat situations. Although the scope of this study was limited to examining performance on a single math test, the outcomes of this research may potentially be used as a basis for guiding educators in the recruitment and retention of females in the math and science fields. Previous stereotype threat intervention research studies have not examined if the central message of the intervention is retained by the participants after completing the study. If the message is not retained, then the intervention will not generalize to other situations after the study. This study also examined if the participants retained the primary message of the intervention one week after completing the study. The central hypothesis of this study was that math performance of female participants would improve when being exposed to the 
concepts and research findings of stereotype threat, and that participants will be able to recall the intervention message one week after completing the study.

Examining the potential differences in causal attributions made for performance in stereotype threat and stereotype threat intervention situations may elucidate the reasons that females decide to forgo completing studies or pursuing careers in math and science fields. It is imperative that researchers examine which factors contribute to females developing stable internal attributions for success on math tasks. Stereotype threat research has previously demonstrated that female students experience performance deficits on math tasks in stereotype threat situations (Steele, 1995; Steele \& Aronson, 1997). However, research in this domain has not previously examined the relationship of causal attributions ascribed to success and failure in stereotype threat and stereotype threat intervention situations. Finally, prior research has not considered the importance of female math and science majors' perceptions of their faculty support as a potential buffer to the effects of stereotype threat. This intervention examined a method for improving math performance of female students in math and scienceoriented fields while in stereotype threat situations, in addition to studying potential relationships between causal attributions, recall of the intervention message following participation in the study, and perceived faculty and departmental support.

Justification for and Significance of the Study

"I'm going to confine myself to addressing one portion of the problem, or of the challenge we're discussing, which is the issue of women's representation in 
tenured positions in science and engineering at top universities and research institutions......My best guess, to provoke you, of what's behind all of this is that the largest phenomenon - by far - is the general clash between people's legitimate family desires and employers' current desire for high power and high intensity; that in the special case of science and engineering, there are issues of intrinsic aptitude, and particularly of the variability of aptitude; and that those considerations are reinforced by what are in fact lesser factors involving socialization and continuing discrimination."

-Lawrence Summers (2005), former president of Harvard University

When we ponder the reasons for which there is a dearth of females in the math and science fields, we need only consider the speech given by the former Harvard University president, Lawrence Summers, in January, 2005. Despite the fact that no differences were found between men and women to succeed in mathematics (NCES, 2004) and in science and engineering (NCES, 2000) one of the most powerful figures in academia told the world that women have inferior natural ability in these fields when compared to men. Women and girls who heard the words of Summers may also hear similar spoken or unspoken messages from their parents and teachers. Little by little, these messages may become internalized to the point that women begin to believe that they are not as capable as men to succeed in the math and science fields. As a result, fewer women decide to pursue advanced studies and careers in math and science. 
Currently, there are fewer females than males earning undergraduate and graduate degrees in mathematics (NCES, 2004), computer science, and physics (NCES, 2000). In 2001, only $23 \%$ of doctoral degrees in mathematics were earned by females (NSF, 2006) and only $8 \%$ of mathematics professors were women (NSF, 2000). In engineering, women earn approximately $19 \%$ of the undergraduate or master's degrees (NCES, 2000) and less than 20\% of the engineering doctorate degrees (NSF, 1998). This shortage of women in the fields of mathematics and the sciences might be understandable if women were less skilled than men at mathematics concepts and computations; however, there is virtually no difference in the math aptitude of high school males and females (NCES, 2004). However, female high school students report that they like math less than male students (NCES, 2004). Women college students studying math reported significantly more discrimination as well as a significantly higher proportion of students considering leaving the field than students in such "female dominated" areas as education and social science departments (Steele, James, \& Barnett, 2002). Across the educational pipeline, there is a progressively greater attenuation of females majoring in math or science fields or pursuing careers in these areas.

In order to understand the mechanisms that influence fewer women to pursue careers in the fields of math and science, this problem has been examined through several theoretical frameworks. These theories include (but are not limited to) stereotype threat, causal attribution, and self-efficacy. The application of each of these theories or domains of research has produced research that 
explains differences in academic performance. Although each of these concepts has driven research examining differential academic performance, scant research has combined these concepts together in order to glean a more comprehensive understanding of the mechanisms at play, particularly when examining the dearth of women in fields of math and science.

Steele (1999) examined why fewer females choose to pursue careers in these fields through his study of stereotype threat, which he defines as "the threat of being viewed through the lens of a negative stereotype, or the fear of doing something that would inadvertently confirm the stereotype" (p. 46). The roots of stereotype threat emerged while Steele was working at the University of Michigan. Steele realized that at every level of math scores obtained by University of Michigan students, females were underperforming in comparison to men in advanced math classes. He also recognized that this same discrepancy was found between African American students and White students at every level of SAT scores obtained.

The effects of stereotype threat can exacerbate the performance of any group for which negative stereotypes exist, however, its effects are particularly pronounced amongst individuals who care most about their performance within the domain (Steele, 1999). It is probable that the most pernicious consequence of stereotype threat lies in the fact that optimally motivated and talented students may convince themselves that they are indifferent to succeeding in a specific academic subject so that they can avoid the anxiety and potential failure that pursuit of mastery in this subject might cause. Females may consequently remove 
the academic subject from their self-concept. This type of academic withdrawal is referred to as disidentification (Steele, 1997; Steele \& Aronson, 1995).

When members of a stereotyped group strive to succeed within the domain for which the negative stereotype for that group exists, disidentification is most likely to take place (Steele, 1997; Steele \& Aronson, 1995). When a student fears confirming a negative stereotype, they may experience repeated bouts of performance-hindering anxiety when they engage in stereotyped domain-related tasks. In order to rid themselves of the discomfort of the anxiety, they may convince themselves that their performance in this domain is unimportant to them, and withdraw this domain from their self-concept. Students may choose to stop applying themselves in a particular domain so that they might escape the anxiety that goes along with their attempts to succeed in the corresponding domain.

Stereotype threat research has focused on the experiences of several racial and ethnic groups to determine the breadth of cultures in which the associated effects of stereotype threat emerges. Consistently, these studies have produced results that illustrate the degree to which a group's performance can be affected by such a threat. For example, when a test was presented as being diagnostic of ability, African American students underperformed in comparison to Caucasian students, yet performed as well as Caucasians when the test was presented as nondiagnostic of ability (Steele \& Aronson, 1995). Similar results were found among Latinos (Aronson \& Salinas, 1997) and with students from low SES backgrounds (Croizet \& Claire, 1998). When the Asian identity of Asian American college students was made salient, their math performance improved yet was hindered 
when their female identity was made salient (Shih, Pittansky, \& Ambady, 1999). These results were replicated in a younger sample of girls enrolled in grade school and junior high school (Ambady, Shih, Kim, \& Pittansky, 2001).

The effects of stereotype threat have emerged amongst other groups, such as the elderly, and even a non-stigmatized group (Caucasian men). In research conducted with elderly participants, the stereotype regarding poor memory skills for the elderly was made salient, consequently resulting in these participants performing significantly worse on memory tasks than when positive characteristics associated with the elderly were activated (Levy, I996). The athletic performance of Caucasians has also been found to suffer when they were compared to African Americans and were told that performance on 10 golf holes was indicative of "natural athletic ability." Conversely, Caucasians outperformed African American participants when they were told that the 10 holes were representative of "strategic sport intelligence" (Stone, Lynch, Sjomeling, \& Darley, 1999). In math, Caucasians experienced performance deficits in the domain of math when stereotypes regarding Asians having superior math skills were made salient (Aronson, Lustina, Good, \& Keough, 1999).

A large body of stereotype threat research has focused on examining the performance-hindering effects suffered by females on math tasks (Ambady et al., 2001; Ambady, et al., 2003; Inzlicht \& Ben-Zeev, 2000; Johns, et al., 2005; Martens, Johns, Greenberg, \& Schimel, 2006; McIntyre, et al., 2003; Shih et al., 1999; Spencer, Steele, \& Quinn, 1999; Steele, 1999). Thus far, stereotype threat research within this domain has produced robust findings which illustrate the 
negative impact that the activation of gender stereotypes has on female performance. When we examine the results of stereotype threat research focusing on gender differences, we may gain insight into the contributing factors to the dearth of females working in the field of mathematics. This research has studied how and why the effects of stereotype threat take place, as well as methods for improving female math performance while experiencing the effects of stereotype threat (Ambady et al., 2001; Ambady et al., 2003; Inzlicht \& Ben-Zeev, 2000; Johns et al., 2005; Martens et al., 2006; McIntyre et al., 2003; Shih et al., 1999).

While there is empirical support of stereotype threat effects, there is criticism of stereotype threat research and its findings. Sackett (2004) published an article in American Psychologist that demonstrated that many popular news magazines and newspapers, as well as psychology textbooks, mistakenly presented stereotype threat as fully explaining the gap in performance between Caucasian and African American students. Sackett argued that stereotype threat research did not fully explain the gap in performance between groups. Sackett and Wax (2004) argue that stereotype threat effects would not generalize to "real world" situations as most stereotype threat research takes place in laboratory settings. There is stereotype threat research that has not demonstrated significant findings (McKay et al., 2002; Rivardo, Rhodes, and Klein, 2008) although it is difficult to estimate how many studies have not found significant findings as these studies are less likely to be published. Despite the fact that there are critics of stereotype threat research, and that all research studies in this area have not 
produced significant results, stereotype threat research has produced interesting results that are the impetus for further research in this area.

Bernard Weiner is a scholar whose research has examined methods for understanding and improving academic performance. He devoted the majority of his life's research to applying the principles of Attribution Theory to the context of academic achievement. Weiner's work, referred to as Causal Attribution Theory (or Attribution Theory in Achievement), examined how individuals perceive their success or failure on academic tasks. Although this theory has been applied to domains other than that of academic achievement, Weiner's work concentrated upon the context of achievement. Weiner believes that Causal Attribution Theory has two major foci: examining how one infers causality, and consequently, exploring how this guides future behavior (Siegal \& Shaughnessy, 1996). When one considers the cause of success or failure on a task, the cause can be attributed to one of four causal attributions: ability, effort, chance, or task difficulty (Weiner, 1972; 1989).

Weiner additionally believed that each of these causal attributions could be examined along three causal dimensions: locus, stability, and controllability (Weiner, 1972; 1989). Locus explains whether a cause can be considered internal (related to the person) or external (related to the environment) (Weiner, 1972; 1989). The dimension of stability refers to whether or not the cause can be considered to change over time (Weiner, $1972 ; 1989$ ). Controllability determines whether or not the cause may be considered controllable (Weiner, 1972, 1989). The causal attribution of ability may be considered internal and stable, effort is 
considered internal, unstable, and controllable, chance is regarded as external, unstable and uncontrollable, and finally task difficulty is considered stable and external (Weiner, 1972; 1989). How one ascribes these different causal attributions to success or failure on tasks can produce different affective responses, affect one's self-esteem, and influence one's expectations for performance on a similar task in the future (Weiner, 1972; 1989; 2006).

Weiner found that causal attributions ascribed for performance on a present task can affect future performance because he found that when an individual attributes failure to a lack of ability, this will lead them to have low expectations for future success, which will cause them to have low self-esteem, and cause them to experience a sense of shame (Siegal \& Shaughnessy, 1996). Conversely, if success is attributed to an external cause such as luck, it will be less likely that an individual will expect to succeed in the future, or feel a sense of pride and enhanced self esteem (Weiner, 1986). Weiner believes that it is possible to change one's attributions for poor performance, potentially affecting performance on a similar task in the future. He found that if you encourage an individual to attribute poor performance to an unstable cause, such as bad luck or low effort, this would raise one's expectations of success in the future and cause one to feel guilt. The guilt could help performance in that it may motivate someone to study and work harder in the future (Siegal \& Shaughnessy, 1996; Weiner, 1972).

Causal attribution theory is applicable to stereotype threat research because it may help us to understand the mechanisms that produce stereotype 
threat effects. Stereotype threat research has demonstrated that individuals in situations high in stereotype threat underperform in comparison to individuals who perform in situations free from stereotype threat. If we unearth a differential causal attribution pattern between groups, we may surmise that stereotype threat influences the degree to which we believe we are in control of our own academic performance. As causal attributions on one task may influence performance as well as performance beliefs on future tasks, causal attribution theory may also contribute to our understanding of the disidentification process.

Self-efficacy is a concept that has long been applied to the domain of academic achievement, and may also help us to understand why disidentification takes place. Self-efficacy is important to consider in academic achievement because self-efficacy has been linked with achievement, the variety and level of difficulty in the tasks one attempts, as well as one's perseverance on a task. Albert Bandura described self-efficacy as "the belief in one's capabilities to organize and execute the courses of action required to manage prospective situations" (1995, p. 2). Bandura and his students have spent over 30 years researching self-efficacy and found that individuals with strong self-efficacy beliefs are likely to attempt a task, to persist and exert greater effort on a task until completion, and will set higher goals for themselves on future tasks than those with low self-efficacy (Meyers, 2002).

Bandura $(1977,1986)$ found that self-efficacy was influenced by four different factors: mastery experience, vicarious experience, social persuasion, and a person's physiological states. Bandura believed that mastery experience 
contributed to the development of strong self-efficacy beliefs due to experiencing repeated successes on a task. Individuals experience the effects of vicarious experiences after witnessing others achieving success at a task. When seeing that others have the capability to succeed, this bolsters the idea that they, too, could succeed at the task. Social persuasion contributes to the development of selfefficacy beliefs in that one will start to believe that they have the skill to succeed if they often hear it. The physiological responses that one experiences when thinking about or actually performing a task sends signals to inform how confident one feels in possibly succeeding on a task. If women are not often made aware of other women succeeding on math tasks, if they do not regularly hear their parents and teachers speak highly of their math skills, and if they experience the physiological responses associated with anxiety in stereotype threat situations, it is possible women may be at risk of not developing strong self-efficacy beliefs in math.

The concept of self-efficacy was first applied to stereotype threat research by Steele and Aronson (1995). They believed that self-efficacy erodes when an individual in a stereotype threat situation starts to doubt their ability to succeed on a task. In later research, Steele asserts that a student may not be performing optimally due to poor self-efficacy beliefs as a result of not identifying with the subject (Steele, 1995). The current study examined self-efficacy in stereotype threat research by looking at the relationship between self-efficacy and causal attributions participants make for success or failure on a math task. The current study examined the relationship between self-efficacy and perceived faculty 
departmental support (discussed later in this manuscript). Previous stereotype threat research has not yet provided solid empirical evidence of the relation of self-efficacy to the concept of stereotype threat. The present study examined the relationship between self-efficacy and social support.

The support of academic departments and professors has not often been examined in research looking at methods for improving academic achievement. As there is a significantly lower number of women enrolled in science and mathematics programs, several researchers have examined the dynamics of these departments to understand why departments attract far fewer female students (Herzig, 2004; Seymour, 1995; Vogt, Hocevar, \& Hagedorn, 2007; Zeldin \& Pajares, 2000). When students are enrolled in departments in which they feel supported, they are more likely to develop a higher level of self-efficacy in their major field or study (Zeldin \& Pajares, 2000). However, when students feel a lack of faculty support and receive insufficient advising, they may decide to leave the department as well as the field of study (Seymour, 1995).

The relationships between female students and their faculty in science and math departments have been examined to assess the level of support perceived by female students (Herzig, 2004; Seymour, 1995). These studies have produced disquieting findings. In Seymour's study (1995) examining the high attrition rates of undergraduate science majors across seven different campuses in the U.S., she found that women students in these departments often felt "intimidated" and "insecure" and questioned if they had chosen to study in the department that best suited them. When Seymour interviewed the faculty, some members 
communicated that female students were not welcome in their classrooms, suggesting that a number of math and science departments in the U.S. are not particularly welcoming to women students. If students do not feel welcome or supported by their departments, they may consider transferring to a different educational setting.

There is evidence that some women graduate students of mathematics experienced difficulties interacting with faculty advisors. Herzig (2004) examined the nature of the relationships between female graduate students of mathematics and their faculty advisors. Many of these students felt that the professors were unfriendly, and at times, even "hostile." Students reported feeling that they received inadequate advising which resulted in their making uninformed decisions about what classes they should take and leading them to be uminformed about what to expect in their program of study. A number of students complained that their professors did not provide sufficient examples to explain the material presented in lectures. When these students asked questions, they felt that they were "rebuffed" in class and often arrived during a professor's office hours to find that the professor was on the phone or had already left.

In addition to feeling rebuffed by professors, many women students attempting to pursue studies in math and science fields have also felt discouraged by their relationships with men classmates. Seymour (1995) found that men were often rude to women in their class. The women students were unsatisfied with the number of interactions they had with other students and felt that men were provided with more chances to communicate with fellow students. One of the 
goals of the current study was to examine if women enrolled in math-oriented departments who feel a lack of support from their faculty are more likely to suffer from the effects of stereotype threat. Additionally, this study examined if faculty support acts as a buffer to stereotype threat effects. Previous stereotype threat research has not yet examined the role of faculty support in preventing stereotype threat effects.

As demonstrated, the theories and concepts of stereotype threat, causal attributions, self-efficacy, and perceived faculty support can be used to help us interpret reasons for differential academic performance. These theories and concepts can also be used to help us to learn how academic performance might be improved. In order to understand how we can improve academic performance by applying these frameworks, it is important to look at the research that has been conducted in each of these domains.

Direct and Indirect Stereotype Threat Activation Methods

Stereotype threat research has attempted to examine the many ways in which stereotype threat effects emerge. The majority of stereotype threat research can be described as employing either a direct (Johns et al., 2005; Martens et al., 2006; McIntyre et al., 2003) or indirect (Ambady et al., 2003; Inzlicht \& BenZeev, 2000) stereotype threat manipulation. Direct manipulation studies typically involve the presentation of an explicit statement to participants. This statement features a stereotype that favors the performance of one group over another. For example, female participants might be told that there is a stereotype which favors the ability of men over women on a particular task (Johns et al., 2005; Martens et 
al., 2006; McIntyre et al., 2003). Researchers may choose to employ direct manipulation strategies to ensure that participants are cognizant of the stereotype regarding female math performance. This method has been used in studies to test an intervention intended to buffer against the harmful effects of stereotype threat (Johns, et al., 2005; Martens et al., 2006). In order to measure the effectiveness of the intervention, the stereotype must be activated.

When research has studied the activation of stereotype threat in a direct fashion, most of the studies have provided a statement to the participants regarding a stereotype about female mathematical ability. Johns et al. (2005) told participants that they would take a math test diagnostic of their true math ability and that performance-based gender comparisons would be made after they finished the test. Martens et al. (2006) told participants to complete a spatial rotation task for which a stereotype exists favoring the performance of men on the task. The researchers stated that the goal of the experiment was to compare the performance of men and women on the task to judge the veracity of this stereotype. McIntyre et al. (2003) employed a similar stereotype activation technique by telling participants that some previous research has shown men outperform women on math tests, but that these findings were inconclusive. These examples all involved a direct method of making the stereotype salient regarding female math performance.

In order to examine how even the most subtle cues may affect the performance of females on difficult math tasks, some researchers (Ambady et al., 2003; Inzlicht \& Ben-Zeev, 2000) preferred to activate the stereotype in an 
indirect fashion. Indirect manipulations generally involve the priming of the female identity of the participant prior to the completion of a math task. An example of an indirect manipulation is asking participants to complete a questionnaire that focuses on issues of gender. Often, the primary focus of these studies is to replicate real world settings in which females perform math tasks to better understand the potential stereotype threat mechanisms at play in the classroom setting.

One research study employed an indirect manipulation so subtle that stereotype threat emerged simply by asking female participants to complete a math test in a group which was outnumbered by males (Inzlicht $\&$ Ben-Zeev, 2000). The stereotype threat activation replicated experiences common to many females in real-world settings, as many advanced level math classes have higher male than female enroliments. In this study, females outnumbered by males performed worse on the math test than females who took the test solely in the presence of other females.

Several other studies have employed an indirect method to activate stereotype threat (e.g., Ambady et al., 2003; Inzlicht \& Ben-Zeev, 2000). When the gender of the participants is made salient, this appears to indirectly prime the stereotype as well. Ambady et al. (2003) utilized an indirect stereotype activation technique which made female gender salient by having participants complete a computer task prior to taking a difficult math task. The participants were told that they needed to identify when a flash appeared on the left or right side of a computer monitor screen. However, the flash was actually one of 20 different 
words related to the female gender (such as aunt, doll, dress, and earring). A second group (a control group) of participants also completed this computer task, but were presented with gender-neutral words that flashed across the screen. When the math test performance of the participants in the gender-primed condition was compared to those in the gender-neutral condition, participants in the gender-primed condition performed worse on the math task (Ambady et al., 2003).

An alternative indirect method for making gender salient prior to completing a math task was utilized in a study by Shih and colleagues (1999) as well as a study by Ambady and colleagues (2001). Participants were asked to complete a questionnaire in both of these studies prior to the math test. The participation in the Shih and colleagues (1999) study were asked questions about their preferences for living conditions, such as their preference for female-only or coed dorms or dorm floors as well as whether or not they would choose to have a male roommate. Ambady et al. (2001) presented participants in grades three through eight with a questionnaire that asked questions such as whether they preferred male or female friends, or if they thought that males were treated differently in school. When gender was primed in both of these studies, the participants performed worse on the math task then when an alterative identity was made salient.

To summarize, the major determinant in deciding to employ a direct or indirect stereotype threat activation method is whether or not researchers want to ensure that stereotype threat effects take place (direct activation), or if they want 
to examine how the most subtle cues can elicit stereotype threat effects (indirect activation). If the goal of the research study is to compare performance in a stereotype threat situation with one where the effects of stereotype threat have been alleviated, researchers will likely choose to use direct activation techniques. Stereotype threat intervention research commonly includes one condition where direct activation techniques are used, one where an intervention is performed, and one condition that acts as the control group. In the current study, two groups were used. A direct activation method was used in the stereotype threat condition in order to ensure that the stereotype is activated. In the intervention condition, an intervention method that has previously been found to be effective was examined. A control group was not used in this study because math test performance is not expected to be different between the control group and the intervention group.

The current study was designed to extend the findings of Frost (2007). Frost (2007) used a direct activation technique to study the effects of stereotype threat. Participants were told that they were taking a math test to study gender differences in ability (stereotype threat condition). One group was placed in an intervention condition which consisted of informing participants about stereotype threat theory. This group's math test performance was compared to the performance of participants in the stereotype threat condition. No significant differences between the groups were found in Frost (2007) but it is possible that the lack of significance was due to several shortcomings of the study. First, as the math test that was used in this study was too difficult for most of the participants, this produced a truncated range of scores. The current study attempted to nake 
the direct activation of the stereotype even more salient than it was in the previous study by telling participants that they were taking a math test to look at gender differences in math ability. However, they were also told that this test had previously been found to determine which females will succeed in math and science-oriented careers and that University of Rhode Island would like to examine which students from the University of Rhode Island will likely be successful. Participants in the teaching intervention condition were also told that males usually perform better than females on the test.

Second, in Frost (2007) participants were recruited from the Introduction to Psychology class at the University of Rhode Island and are typically freshmen and sophomores enrolled to meet a broad liberal arts foundation. The students represented a normal distribution in math skills. The current study recruited participants with more advanced math skills. The study also increased the salience of the direct activation technique and combined with the change in the pool of participants, it was hoped that stereotype threat effects would be diminished. Studies Examining Why Stereotype Threat Effects Exist

Stereotype threat effects emerge in a number of different experimental conditions and among several populations. Since Steele conceived the theory of stereotype threat, he and a number of other researchers have tried to unearth the precise mechanism(s) that contribute to the experience of stereotype threat. In Steele and Aronson's (1995) first published stereotype threat study, they postulated that there may be several potential moderators contributing to stereotype threat effects. They believed that when individuals are in a situation 
where stereotype threat is high, they might suffer from low self-efficacy, evaluation apprehension, anxiety, and low performance expectations. Several studies have sought to explore these as the potential moderators of stereotype threat (Cadinu, Maass, Frigerio, Impagliazzo, \& Latinotti, 2003; Oswald \& Harvey, 2001; Spencer et al., 1999).

Researchers have been unable to provide strong support for the moderators Steele believed contributed to stereotype threat effects (low self-efficacy, evaluation apprehension, anxiety, and low performance expectations). Spencer et al. (1999) studied evaluation apprehension, anxiety, and self-efficacy in relation to stereotype threat effects. Evaluation apprehension and self-efficacy were not found to be mediators on the effects of stereotype threat, and anxiety provided a minimal contribution. Oswald and Harvey (2001) examined potential moderators, finding that state self-esteem, anxiety, and self-efficacy did not relate significantly to stereotype threat effects. When examining performance expectancy, results showed that this factor contributed significantly to stereotype threat effects in that the performance of participants correlated positively with their level of performance expectancy (Cadinu, et al., 2003). Stereotype threat researchers are still analyzing exactly what factors contribute to its associated effects. It is possible that stereotype threat may be better understood if different mechanisms are examined, such as the causal attributions made for performance in success or failure in stereotype threat situations. Although the specific mediators or mechanisms of stereotype threat are not yet fully understood, research has found a 
number of conditions in which performance improves in stereotype threat situations. This research will be examined below.

The Improvement of Female Math Performance

In order to examine a method for improving female math performance in stereotype threat situations, researchers made salient an identity associated with positive math-related stereotypes. Shih and colleagues (1999) examined the two cultural stereotypes concerning math abilities which exist for Asian females:

Asians are stereotypically considered to have superior math skills when compared to other ethnic groups, and females are stereotypically considered to have inferior math skills when compared to males. This study examined the effect of activating more than one social identity of Asian American women in order to study if the participants' performances on the math test would vary according to the identity that was activated prior to taking the test. Participants answered questions which focused on the designated stereotype of the group (female or Asian identity). When the Asian identity of the participants was made salient, they performed better than the participants whose gender identity was made salient. Shih et al. (2001) produced similar results in a study including children in kindergarten through eighth grade. Although it is promising to find conditions in which female math performance improves, not all women and girls belong to groups for which multiple stereotypes exist regarding their mathematics abilities. It is important that future stereotype threat research focus on finding interventions that are applicable to girls and women from any ethnic background. 
There are a number of researchers who have focused on methods for improving female math performance in stereotype threat situations not limited to single cultural groups (e.g., Ambady et al., 2004; Gresky, Eyck, Lord, \& McIntyre, n.d.). The common feature of these studies is that they all focused on making salient the diverse roles and characteristics a woman possesses. The interventions conducted in these studies asked participants to focus on what makes them unique to make them feel that they stand out from their in-group. For example, Martens and colleagues (2006) examined the math test performance of participants in a stereotype threat situation who completed an act of selfaffirmation. The self-affirmation exercise consisted of having participants rank order 11 characteristics or values in order of personal importance (such as sense of humor, relations with friends and family, and physical attractiveness). After rank ordering these characteristics, participants were asked to write why their most valued characteristic was most important to them. When participants completed the self-affirmation exercise, they performed significantly better on a math test in a stereotype threat situation than those who did not complete this exercise.

When participants were asked to consider the many roles and identities they possess, stereotype threat effects were resisted. When participants were asked to consider the many layers of their personal identity, female participants were protected from stereotype threat effects on a math test. Gresky and colleagues (n.d.) found female math performance improved after participants completed a self-concept map of the many roles and identities they possess in life. 
The participants, who completed a self-concept map which listed as many identity characteristics as possible, performed better on the math test than the group who were asked to list only a few characteristics. In both studies (Martens et al., 2005; Gresky et al., n.d.), the participants were protected from experiencing the performance-hindering effects of stereotype threat when they were asked to consider the characteristics that make them unique. Although these results provide insight into understanding the ways we might improve female math performance in stereotype threat situations, it is important that we focus on finding less timeconsuming interventions to implement. To be applied in a school setting, interventions need to take as little time as possible to ensure ready application. The current study examined an intervention that could be easily implemented in a school setting.

McIntyre et al. (2003) conducted two stereotype threat intervention experiments directing participants to focus on the identities of accomplished females, rather than focus on one's individual identity. In the first study, the female participants were told that they were participating in the experiment to help standardize new questions for the GRE quantitative section. These participants were informed that only females would be used for the standardization process because "women produce more reliable and valid data, comprehend the task requirements better, and produce better results in all types of psychological experiments" (McIntyre et al., 2003, p. 84).

Results showed that the participants who read about the "advantage" of using female participants obtained more correct responses on the math test than 
those who did not read this. In the second experiment, the stereotype regarding female math skills was made salient when a male experimenter told participants that "research has shown men to perform better than females on math tasks" yet states that "empirical research is non-conclusive" (p.86, McIntyre et al., 2003). The participants then read four brief essays describing either a female's or a corporation's success in a variety of different fields. After reading the short essays, participants completed a math test. Results showed that when participants read essays about the success of females, they obtained a larger percentage of correct answers on the math problems than the females placed in the control group or the females who read essays about successful corporations. Although female math performance improved when participants were made to consider the achievements of others, this research does not help to explain the specific mechanisms that contributed to this improved performance. It is through the application of attribution theory to stereotype threat research that we may develop a better understanding of how to improve female math performance that has been negatively affected by stereotype threat.

To summarize, a number of different methods have been found to be effective in impeding stereotype threat effects from taking place amongst women on math-related tasks (Ambady et al., 2004; Gresky et al., n.d.; Martens et al., 2005; McIntyre et al., 2003; Shih et al., 1999). Although it is promising to see an array of methods effective in experimental settings, it is necessary for researchers to examine methods that may easily be adapted to the classroom setting to prevent girls from disidentifying with the field of mathematics. The studies conducted by 
Shih and colleagues (1999) as well as Ambady et al. (2004) would be difficult to adapt to the classroom setting as they rely on making positive math-related stereotypes. As not all women belong to groups for which positive math-related stereotypes exist, this intervention method would be limited to a small population of women in the U.S. (e.g., Asian American women). The other studies (e.g., Gresky et al., n.d.; Martens et al., 2005; McIntyre et al., 2003) all rely on techniques that would also be difficult to perform in the classroom. It seems improbable that teachers would ask students to complete a self-affirmation exercise (Martens et al., 2005), draw a self-concept map (Gresky et al., n.d.), or reflect upon successful women (McIntyre et al., 2003) before each math test. To overcome these weaknesses, the present study employed a method to teach women about the concept of stereotype threat and endeavored to ensure that all participants understood the major concepts of stereotype threat theory.

The present study also examined whether or not participants recalled the stereotype threat message taught to them one week after they have been taught about the concept. To date, previous stereotype threat research has not examined whether or not participants can retain the intervention message, yet it is a necessary factor to consider if the goal of stereotype threat research is to deter its associated effects.

Effect of Making Attributions for Potential Failure

Some principal tenets of attribution theory have been applied in stereotype threat studies to examine how performance might improve when participants are asked to attribute potential failure to an external source (Brown \& Josephs, 1999; 
Good et al., 2003; Johns et al., 2005; Wilson \& Linville, 1985). Weiner, one of the leading Attribution theorists who applied the theory to the domain of achievement, stated that "attribution theorists are concerned with perceptions of causality, or the perceived reasons for a particular event's occurrence" (Weiner, 1989, p. 280). Weiner concluded that there are three major causal dimensions which contribute to the manner in which one attributes their success or failure on a task: locus of causality (internal or external), stability, and controllability (Wilson, Damiani, \& Shelton, 2002). Locus of causality refers to whether or not an individual attributes failure to an external source (e.g., difficulty of task) or an internal source (e.g., lack of ability). The causal dimension of stability refers to whether or not the individual sees the causes of failure in achievement as stable and unchangeable or as something that is temporary and changeable in the future. The level of controllability describes if performance is attributed to something an individual has the ability to control (such as skill or efficacy) or something one can't control such as mood or luck (Wilson et al, 2002).

The causal dimensions outlined by Weiner may be applied to stereotype threat situations because those who experience stereotype threat may doubt their ability to successfully perform a task. If an individual doubts their ability to succeed on a task, they may attribute potential failure to an internal source such as lack of ability. When failure is attributed to an internal source such as lack of ability, one may experience anxiety. This anxiety may interfere with an individual's ability to complete a task efficiently, consequently causing one to experience increasingly more anxiety and greater difficulty in completing such 
tasks in the future. This entire process has been described as an exacerbation cycle (Storms \& McCaul, 1976). When an individual repeatedly feels distressed while performing tasks which produce increased amounts of anxiety, they may eventually disidentify with the domain in order to escape these negative sensations. Conversely, if an individual attributes potential failure (or its associated anxiety) to an external source (such as insufficient time to prepare or the setting being too noisy), performance may improve. Studies have shown that academic performance improves when individuals are invited to attribute difficulties to an external source.

Academic performance improved in college freshmen when these students were asked to attribute their difficulties to issues of transitioning to college. Wilson and Linville (1985) implemented an intervention aimed at improving the performance of freshmen college students experiencing academic difficulties by asking students to attribute academic difficulties to a temporary, external source. The students were told that the difficulties they experienced during their first semester were common to college freshmen and were the result of difficulties in transitioning to the college setting. The researchers showed them statistics of average grade increases in the second year of school. In addition, students watched videos of older students discussing how they, too, experienced difficulties transitioning to college their freshman year and that their grades improved over time. The results of this study showed that when students were taught that their academic difficulties were common to students transitioning to a new academic setting, the students' Grade Point Average (GPA) improved in their 
second year of college. These students were also more likely to stay in school and not drop out. When students are presented with "proof" that other students have similar experiences to them, they may be more likely to believe that their plight is not unique to them and feel motivation to persevere.

Attribution theory was also applied to stereotype threat research conducted by Brown and Josephs (1999). Their study informed participants that they would complete a math test while participating in the study. The researchers gave the participants the impression that they would be able to prepare for the math test by completing practice exercises on a computer prior to taking a math test. However, once the participants arrived at the computer to prepare for the test, they were told that the computer crashed and that they would have to take the test without completing the practice exercises. They examined whether or not math test performance would improve when participants were allowed to attribute potential failure to an external rather than an internal cause. When women participants attributed their potential failure to an external cause (the computer "crashing"), they performed as well as the men. However, when the women were not able to attribute failure to an external source, they performed worse than the men on the math test. Allowing participants to attribute possible failure to an external controllable source is a method used in research to improve performance in a stereotype threat situation.

Academic performance improved in junior high students when the students attributed their difficulties to issues associated with transitioning to a new school. Good et al. (2003) implemented an intervention examining the role of 
attributions as a potential buffer against the effects of stereotype threat on standardized tests. Students were asked to attribute their transition to a new school (junior high) as the reason for which they experience any academic difficulties. Researchers examined if this intervention improved the standardized test performance of women, minority students, and students from lower socioeconomic backgrounds. College student mentors were assigned to individual students to meet in person and correspond via e-mail. The message communicated by the college student mentors was that many students start to believe they are incapable of high academic achievement during times of difficult transition yet they often overcome these difficulties and perform better in school during eighth grade. Results demonstrated that women and men performed equally well on the math portion of standardized tests when placed in the attribution condition, whereas men outperformed women on the math test when placed in the control group. The results of this study as well as that by Wilson and Linville (1985) have produced promising results showing that academic performance can improve when students are taught that their academic difficulties are due to an external cause such as transitioning to a new setting. If we are interested in improving performance for students who are not transitioning to a new setting, or the performance of students who have already transitioned, it is important to consider a more straightforward intervention technique. The present study employed an intervention less cumbersome and also not limited to students transitioning to a new school. 
In a study on stereotype threat conducted by Johns and colleagues (2005), participants were also provided with an external source to which they could attribute any difficulties they experienced. They examined if performance in a stereotype threat condition would improve when participants were taught about stereotype threat and warned that any anxiety experienced during the task would be due to stereotype threat, and not a lack of ability. This study compared the math test performance of participants in three different conditions: The math test condition, the teaching intervention condition, and a control group. In the math test condition, participants were led to believe that they would be completing a standardized math test to study gender differences in math ability. The teachingintervention condition informed participants that they were taking part in a study to examine gender differences in mathematical ability, yet were also taught about the concept of stereotype threat. The researcher emphasized that they could attribute any anxiety that they experienced during the task to stereotype threat, and that they shouldn't allow this to interfere with their performance. When these participants were aware of the effects of stereotype threat, and cautioned to prevent anxiety from interfering with their performance, women performed equal to the men in the same condition. The participants in the teaching-intervention condition also performed better than the participants in the math-test condition. This study used an innovative yet simple intervention approach by explaining the phenomenon of stereotype threat. When participants were asked to attribute anxiety to an external source (stereotype threat) they did not experience performance deficits. 
Johns et al. aimed to "release stereotype-threatened individuals from assuming that the increased arousal that they are feeling indicates that they do not have the ability to do well" (Johns et al., 2005, p. 176). In addressing stereotype threat and the performance-hindering anxiety which often accompanies it directly, the exacerbation cycle described by Storms and McCaul (1976) is halted. Instead of allowing the experience of anxiety to convince participants that they may fail on the task due to lack of ability, the participants are able to attribute this anxiety to an external source - stereotype threat. Results of the study by Johns et al. (2005) show that individuals can be protected from experiencing performance deficits due to stereotype threat effects when they have an external source to which they can atribute physiological arousal. When the participants of this study were not provided with an external source to which they could attribute anxiety (math test condition), they performed significantly worse on the math task.

The results from the aforementioned studies (Brown \& Josephs, 1999; Good et al., 2003; Wilson \& Linville, 1985) all produced evidence demonstrating the effectiveness of attributing potential failure to an external source. However, we need to find interventions that can be easily implemented in the classroom. Interventions such as the one performed in the study by Brown and Josephs (1999) would be cumbersome to administer in a college or school setting, as students do not typically believe they will perform practice problems before tests. The interventions in the studies by Wilson and Linville (1985) and Good and colleagues (2003) use an element of deceit. It will also not be possible to prevent stereotype threat effects by telling students that they will perform better after 
transitioning to something new, as students are not always going through a transition.

By providing a straightforward explanation of stereotype threat effects, the intervention used in the study by Johns et al. (2005) uses an honest, nonduplicitous approach that appears to present material that may be retained even after completing the study. Frost (2007) used the straightforward explanation of stereotype threat in the experimental condition but failed to avert the effects of stereotype threat. One reason that could account for the lack of statistically significant findings in Frost is that some participants reported that they misunderstood the concept of stereotype threat and completed the experiment believing the contrary message (that men are better than women at math). The present study aimed to make the message of stereotype threat more salient and clear by showing participants a video of Claude Steele describing the theory of stereotype threat and presenting his research at the Multicultural Summit Conference. After participants watched the video, they were asked to answer four questions regarding the material they viewed, and the experimenter reviewed the answers with the group to ensure that all participants understood the appropriate message before proceeding with the study.

\section{Retention of Stereotype Threat Message}

When researchers have examined the effectiveness of interventions to impede stereotype threat effects from occurring, they have studied the effects of these interventions in one situation on one day. Stereotype threat research has not explored if participants are still able to be buffered from stereotype threat in the 
future, after partaking in the intervention and completing the study. If we are interested in examining methods for stopping the effects of stereotype threat as well as stopping disidentification from taking place, we need to examine if participants can recall the message they were taught after participating in the study. If we find that participants are able to retain the message after participating in the study, then we may examine if the intervention is still effective at a later date. If we learn that interventions are effective long-term, then we may begin to find a method for discouraging disidentification from taking place. Self-Efficacy and Academic Achievement

Several researchers have found a link between one's self-efficacy in a particular domain and the causal attributions that one forms for performance in that domain. Bandura (1986) believed that an individual's perception of their ability to be efficacious on a task helps to form causal attributions for performance within that domain. This influences future performance because one's attributions for performance will affect their beliefs about being efficacious on a task in the future (Bandura, 1986). The present study aimed to examine the potential relationship between one's level of self-efficacy and the causal attributions made for their performance on a math test. Although self-efficacy and causal attributions have not yet been studied in relation to stereotype threat, they have been previously investigated.

For example, some research has shown a relationship between expectations of self-efficacy in social situations and the causal attributions made for the outcome of this encounter. Alden (1986) provided participants with a 
description of an individual making the acquaintance of a stranger. Participants were asked to rate whether or not they would handle this situation with ease. Based on their ratings, participants were placed in "high" and "low" self-efficacy groups. After the initial rating took place, participants met with the experimenter individually as well as a second person who acted as the "collaborator." The participant was told that they were expected to engage in a conversation with the collaborator in order to get to know the person better. Ten minutes into the conversation, the participant was told that they would be rated on their ability to communicate with the collaborator. The collaborator gave the participant feedback regarding their communication skills. If this feedback was inconsistent with their expectations (the participant was given a poor rating by the collaborator although they were initially placed in the "high" self-efficacy group) the participant was more likely to attribute the outcome to an external factor (the setting or the collaborator's communication abilities). Participants placed in the "low" self-efficacy group, given a rating by the collaborator that was inconsistent with their expectations (they were given a high communication rating although they expected to be unsuccessful) also attributed the outcome to an external cause. This study showed that when individuals are given feedback that they are not expecting to receive, they are more likely to attribute the outcome of the task to an external factor.

In another study looking at the relationship between self-efficacy and causal attributions for performance, Schunk and Gunn (1986) examined how attributing success on a math task to an internal cause (high ability) was most 
likely to show increases in self-efficacy. In this study, students were taught math problem-solving strategies during four 40 -minute periods over several consecutive days. The participants completed a measure of self-efficacy prior to the training, and also after they completed the training and a scale measuring causal attributions made for performance. Results demonstrated that when participants attributed the cause for their success on the math problems to "high ability" they were more likely to show increases in the measure of self-efficacy. This is consistent with Bandura's theory regarding the relationship between selfefficacy and causal attributions; attributions can cause changes in self-efficacy (Bandura, 1977). One of the goals of the present study was to compare the causal attributions made for success and failure by participants in a stereotype threat condition with those in a stereotype threat intervention condition. If we see that individuals attribute their success and failure differently, and additionally differ in their levels of self-efficacy, this will provide us with greater insight into how we might deter disidentification from taking place.

When individuals demonstrate high levels of self-efficacy, they are more likely to attribute their performance to stable and controllable conditions. The relationship between self-efficacy and causal attributions made for performance were examined in a study that used bike ergometers. McAuley, Duncan, and McElroy (2001) randomly assigned participants to one of two conditions: high self-efficacy with a success outcome and low self-efficacy with a failure outcome. The participants in the high self-efficacy condition rode bicycles rigged to allow them to win three trial races. Winning the three races allowed them to gain a sense 
of "mastery experience" which has been found to be related to self-efficacy development. After racing the bicycle, participants were asked to rate how well they thought they would perform in a future race (in order to verify that they demonstrated high self-efficacy) as well as complete a measure of self-efficacy. Results showed that the participants who viewed themselves as more successful on the task (those with high self-efficacy) attributed their performance to more stable and controllable conditions. When individuals believe that they are in control of performing well on a task and they attribute their performance to an internal causal dimension, their levels of self-efficacy have been found to increase, which may influence future successes on a task.

Stereotype threat research has not previously examined the relationship between self-efficacy and causal attributions made for success and failure. Understanding the relationship between these two variables will better inform us about how to create successful interventions for women in math-oriented classes and fields of study. If we find that women in stereotype threat intervention conditions demonstrate higher levels of self-efficacy and also make more internal attributions for their success on a task, we will have a better idea of the mechanisms at play in stereotype threat conditions and will be better equipped to combat the performance-hindering effects of stereotype threat.

Faculty Support of Females in Math and Science Fields

When students feel that they are supported by their faculty, they are more likely to complete the degree and succeed academically (Nesbitt-Shelton, 2000; Vogt et al., 2007). When Nesbitt-Shelton administered the Perceived Faculty 
Support Scale to female nursing students, results demonstrated that students who obtained higher scores on this measure were more likely to complete the degree and obtain high grades while enrolled in the program. Nesbitt-Shelton administered the Perceived Faculty Support Scale and a measure of self-efficacy to students currently enrolled in a nursing program and also to students who had withdrawn from the program. Results showed that perception of faculty support coupled with level of self-efficacy predicted persistence (staying in the program) and academic performance or (GPA). That said, when participants had higher levels of perceived faculty support and self-efficacy, they were more likely to complete the program and earn a higher GPA. Perceived discrimination and selfefficacy were inversely related in a study conducted by Vogt and colleagues (2007). Vogt et al. (2007) found that females who demonstrated lower levels of self-efficacy also reported higher levels of perceived discrimination. This study additionally found that high levels of self-efficacy were the strongest determinant for high GPAs. Therefore, female students perceiving high levels of discrimination may obtain lower GPA's.

Research has shown that a higher level of self-efficacy is found in women students who feel a stronger sense of support by faculty members and the department (Lent, et al., 2001; Vogt et al, 2007). Several studies have found that students who have a strong sense of self-efficacy in various academic domains also perform well academically (Pajares, 1996; Pintrich \& DeGroot, 1990; Zimmerman, Bandura \& Martinez-Pons, 1996). Jacobs, Prentice-Dunn, and Rogers (1984) showed that levels of self-efficacy expectancy correlate with the 
amount of time that one persists at a task. This study asked participants to complete a series of perceptual motor and anagram tasks. Each participant was provided feedback that suggested the participant was not succeeding on these tasks. After completing several tasks, participants were asked to complete a measure of self-efficacy expectancy that measured how well they expected to perform on the next task. Finally, the participants were told that their last task was an untimed task. The amount of time that a participant persisted on the task was correlated with their level of self-efficacy expectancy suggesting that individuals who show high levels of self-efficacy in a domain are more likely to spend more time trying to be successful on a task, and were consequently more likely to be successful.

Since persistence is important in completing individual tasks, courses, and degrees, one may see its importance in students developing a strong sense of selfefficacy. This further supports the need for math and science departments to ensure that female students feel supported to persist in their fields of study by faculty and the department. If math and science departments were to provide greater departmental and faculty support, female students may have higher levels of self-efficacy and academic success.

Some females in math and science departments in U.S. universities appear to feel that they do not receive optimal support by their faculty and departments (Vogt et al., 2007). However, there are certainly some female students who are studying in departments that provide great support in furthering the academic growth of all students. Previous stereotype threat research has not examined 
whether or not a sense of strong faculty support can act as a buffer against the effects of stereotype threat. Examination of perception of faculty support in the context of stereotype threat, as well as the relationship of this factor to levels of self-efficacy, will help us to understand how to draw and retain more females in male-dominant fields of math and science.

Goals of the Current Study

This study examined the potential mechanisms that prevent women from pursuing studies and careers in these fields. Past research has demonstrated that simply teaching women about the concept and dangers of stereotype threat has, in some contexts, buffered them against the harmful effects of stereotype threat (Johns et al., 2005). As this intervention has produced inconsistent results, the present study sought to deepen our understanding of the conditions under which learning about stereotype threat effects leads to buffering effects. Additionally, this study examined the causal attributions individuals ascribe for their success or failure on a task. This study also examined participants' sense of self-efficacy to potentially inform faculty of females in math and science departments. Past research has shown that individuals with a greater sense of self-efficacy are more likely to attribute success on a task to an internal source, such as ability or effort (Alden, 1986; McAuley, et al., 2001; Schunk \& Gunn, 1986). The relationship between these two factors has not previously been considered in stereotype threat research. As individuals who have a greater sense of self-efficacy are more likely to be successful in attempting tasks in said domain, it is important to examine the relationship between these factors when females are in a stereotype threat 
intervention condition as well as in a condition where the effects of stereotype threat are present. We must additionally consider the importance of perceived faculty support for female students in the fields of math and science in the context of stereotype threat conditions. Past studies have shown that when females who are studying in the math and science fields feel that they are supported by their faculty and departments, they demonstrate greater academic achievement (Nesbitt-Shelton, 2000; Vogt et al., 2007) as well as a greater sense of selfefficacy (Lent, et al., 2001; Vogt et al, 2007). An exploration of the relationship between perceived faculty support and self-efficacy while in stereotype threat and stereotype threat intervention conditions may further elucidate stereotype threat research. Finally, this study examined if participants in the intervention condition can retain the stereotype threat message one week after participating in the study. Statement of Purpose

There were eight aims to this study. One purpose was to examine a stereotype threat intervention that can be easily administered, applicable to girls and women whose message is retained even after the participants have completed the study. Another aim was to examine potential differences in causal attributions between females who were informed about stereotype threat with those who were not. This study also compared the math test performance of women who feel that they are supported by the faculty with those who felt they received insufficient support in their academic departments. This research study may potentially deter women from experiencing performance deficits in stereotype threat situations. As a result, the study's intervention may influence more girls to choose to study 
math-oriented subjects in college, as well as retain women in the field who are currently studying math-oriented subjects in college. This intervention may also help researchers to better understand the mechanisms that contribute to stereotype threat, in addition to better informing educators how to provide the support that female students need to succeed in math-oriented subjects.

Research Hypotheses

Hypothesis 1: When women participants are informed about the concepts and dangers of stereotype threat by viewing a video of Claude Steele speaking about stereotype threat theory and research (Teaching Intervention condition), they will perform better on a math test than women in another group: Those who are told the results of their math test will be compared with that of men (Stereotype Threat condition).

Hypothesis 2: When women participants are informed about the concepts and dangers of stereotype threat (by viewing a video of Claude Steele speaking about his theory and research), they will make more internal attributions for their success on the test (McAuley, Duncan, \& Russell, 1992) on three factors: locus of causality, stability, and personal control. When women are not informed about the concepts and dangers of stereotype threat, they will be more likely to believe that their failure is due to internal attributions (participants will obtain lower scores on the external control factor of the Causal Dimension Scale II).

Hypothesis 3: When participants are taught about the concept and dangers of stereotype threat by watching a video of Claude Steele, participants will be more likely to retain the central message than participants who are provided with 
a description of stereotype threat in a written debriefing statement. The research of Craik and Tulving (1975) demonstrated that information is more likely to be retained when individuals gain understanding of the material. Consequently, when presented with four questions about stereotype threat (see Appendix I), more correct answers will be obtained one week after participating in the experiment from the participants in the teaching intervention condition than the participants in the stereotype threat condition. Participants in the Teaching Intervention condition are expected to achieve an average of $60 \%$ of the questions correct one week after participating in the study (Moseley, Wiggins, \& O'Sullivan, 2006). This particular score estimate is chosen in order to demonstrate that the expected difference is greater than chance.

Hypothesis 4: Based on previous theory and empirical research on perceived faculty support, (e.g., Nesbitt-Shelton, 2000; Vogt et al., 2007), selfefficacy (e.g., Pajares, 1996; Pintrich \& DeGroot, 1990; Zimmerman, Bandura \& Martinez-Pons, 1996), and counteracting stereotype threat (Johns et al., 2005), the following hypotheses are made:

4A: There will be a positive correlation between perceived faculty support and math test scores; Perceived faculty support will predict performance on the math test.

4B: There will be a positive correlation between self-efficacy and math test scores; Self-efficacy will predict math test performance on the math test. 
4C: There will be a positive correlation between treatment condition (Teaching Intervention) and math test scores; Treatment condition will predict math test performance on the math test.

4D: There will be a positive correlation between the interactions between selfefficacy and perceived faculty support; This interaction will predict math test performance.

4E: There will be a positive correlation between the interaction of self-efficacy and internal attributions; This interaction will predict performance on the math test.

\section{Method}

Participants

Participants in this study included 100 women (no men participated). Only women were included in the study because the researcher was interested in only comparing the performance of women in two different conditions. The total number of participants necessary was calculated using power analysis. The study conducted by Johns et al. (2005) yielded an effect size of $d=0.82$. In calculating the power analysis with the expectation of producing a medium effect size, a minimum of 30 participants were necessary for each group. This required a minimum total of 60 participants. There were 50 women in each condition of the $2 \times 1$ factorial design. These conditions consisted of two conditions (teaching intervention or stereotype threat condition). 
Eighty participants (80\%) in this study self-identified as "White/European American," $8(8 \%)$ as "Black/African American," $6(6 \%)$ as Asian, $5(5 \%)$ as Hispanic, and $1(1 \%)$ as "Other race/ethnicity." Participants were asked to indicate their year in school. Thirty (30\%) identified as freshmen, $32(32 \%)$ identified as sophomores, $28(28 \%)$ identified as juniors, and $10(10 \%)$ identified as seniors. When the participants were asked to indicate the number of math classes they had taken in college, $45(45 \%)$ responded that they had taken four classes, $33(33 \%)$ responded that they had taken three classes, and $22(22 \%)$ responded that they had taken five classes. Participants were also asked to indicate their quantitative SAT score. Unfortunately, due to the introduction of the new SAT in recent years, participants responded without indicating which version of the test they took. This makes these results impossible to compare. The quantitative SAT scores that were reported ranged from 550 to 780 .

\section{Measures/Instrumentation}

The participants completed four measures: the math test, the Causal Dimension Scale II (CDS-II), the General Self-Efficacy Scale, the Perceived Faculty Support scale, and a demographic survey.

\section{Math Test}

The math test consists of 20 multiple choice questions taken from the Graduate Record Examination (GRE) test guide (Educational Testing Services, 1994) (see Appendix A). This test includes problems focusing on algebra, geometry, and computational skills. In a previous administration by Educational Testing Services, $36.6 \%$ of examinees answered all the questions correctly 
(Educational Testing Service, 1994). When this test was administered in past stereotype threat research, participants obtained scores ranging from $\mathrm{M}=.55$ (Standard Error $=.05)$ to $\mathrm{M}=.70($ Standard Error $=.05$ ) based upon the experimental condition they were placed in (Inzlicht \& Ben-Zeev, 2000). Standard error refers to the estimated standard deviation of the error. Scores for this test were computed by dividing the total items correct by the total items attempted (Steele, 1995). Internal consistency reliability was computed using Cronbach's coefficient alpha and was found to be .49 in previous research (Frost, 2007). Cronbach's coefficient alpha is a reliability measure used to indicate the degree to which different items on a scale measure the same construct. When Cronbach's coefficient alpha is low, the data is likely measuring several factors rather than a single factor, or the items might be poorly worded. As the reliability value obtained in the previous administration of the test was low, there was some concern as to whether or not it would be acceptable to use this test again. After consulting with an ETS test representative (on April 12, 2008), the researcher learned that the reliability value (Cronbach's coefficient alpha) was .89. As this is a high reliability value, this test was determined appropriate by committee members during communications in Spring 2008. No further information regarding the psychometric properties of this test are available.

\section{Causal Dimension Scale (CDS II)}

The CDS II was developed by McAuley, Duncan, and Russell (1992) to measure the causal attributions one makes for performance (see Appendix B). This scale is a semantic differential measure consisting of 12 items which assess 
four dimensions of causal attributions. The four dimensions include: locus of causality, stability, personal control, and external control. The four dimensions represent different separate subscales and each contains three items. Each of the 12 items is scored on a 9 point scale. Each subscale score ranges from 3 points to 27 points. Higher scores represent attributions that are more internal, stable, personally controllable and externally controllable. Previous research has found coefficient alpha values for the four subscales: locus of causality $=.60$ to .71 , stability $=.66$ to .68 , personal control $=.72$ to .90 , and external control $=.71$ to .92 (McAuley et al., 1992). No further psychometric information exists for this scale. CDS II data were analyzed using Multivariate Analysis of Covariance (MANCOVA) contributing to four dependent variables: locus of causality, stability, personal control, and external control.

\section{General Self-Efficacy Scale}

The General Self-Efficacy Scale was created by Jerusalem and Schwarzer (1995). This is a 4-point 10 -item Likert scale $(1=$ not at all true, $4=$ exactly true $)$. The scale is used to measure an individual's sense of competence in efficiently dealing with stressful situations. High scores on this scale indicate that an individual feels a strong sense of competence in dealing with stressful situations whereas a low score indicates that an individual does not feel competent dealing with stressful situations. The scale has been found to have internal consistency values of .75 and .90 as measured by Cronbach alpha. No other psychometric information is available about this scale. A copy of the scale appears in Appendix C. 


\section{Perceived Faculty Support Scale}

The Perceived Faculty Support Scale was created by Nesbitt-Shelton (2003) to measure the degree students feel supported by their faculty. This is a 7point 24 -item Likert scale ( $1=$ Strongly Disagree and $7=$ Strongly Agree). Factor analysis of the scale revealed two factors: Psychological Support and Functional Support (Nesbitt-Shelton, 2003). The factor of Psychological Support measures the participant's sense that they are supported in developing competence and self worth. The factor of Functional Support measures the degree to which participants feel supported in persisting to achieve academic success. Full scale scores on this measure range from 24 points to 168 points. High scores on this measure indicate that an individual perceives a strong sense of support by their faculty members. Full scale scores were used to interpret this scale. The reliability of this scale is .94 , as measured by Cronbach alpha. No other psychometric information is available about this scale. A copy of the scale appears in Appendix D.

\section{Demographic Survey}

After participants completed the Perceived Faculty Support Scale (NesbittShelton, 2003), they answered a brief questionnaire which asked them to indicate their gender, racial/ethnic background (American Indian or Alaska Native, Asian American, Black or African American, Native Hawaiian or Other Pacific Islander, White, Hispanic or Latino, or Some Other Race), math courses completed (algebra, geometry, advanced algebra, trigonometry, calculus, and advanced calculus) and prior SAT Quantitative scores obtained (see Appendix E). 


\section{Procedures}

Participants were recruited from various departments and groups at the University of Rhode Island in which women students who major in math and science fields are affiliated. These included the residences or groups such as the Women's Center, the International Engineering Program house, and residence halls that house students in science and math fields. Participants were also recruited from University of Rhode Island student groups such as the Student Women Engineers group, the Society of Hispanic Engineers, and the Society of Black Engineers. The researcher visited the meetings of these student residences and groups, and also classes (such as MTH 244 Differential Equations MTH 243, Calculus for Functions of Several Variables CHM 212, Quantitative Analysis EGR 106, Foundations of Engineering II CHM 227, Organic Chemistry II and PSY 113 Introduction to Psychology (only students who have completed advanced math classes and majored in specific math or science-oriented programs), when provided permission by the professor) during the Spring and Summer semesters of 2008. Participants were provided instructions explaining how long the study takes to complete and how they could sign up to participate (see Appendix F). Participants were also provided with a variety of days and times in which they could participate in the study and were asked to indicate their availability. Once the researcher communicated with potential participants by email and arranged a time for them to participate in the study, participants were assigned to one of two conditions: Teaching intervention or stereotype threat. All individuals who chose to participate in the study were entered into a raffle which 
made them eligible to win $\$ 100$. Once participants signed up to participate in the study, they were assigned to one of two conditions to complete the experiment. All sessions were run by the experimenter.

Once assigned to a condition, participants first completed the informed consent form (Appendix G). The participants in the teaching intervention condition (see Appendix $\mathrm{H}$ ) viewed seven minutes of a video of Claude Steele giving a presentation at the 1999 National Multicultural Conference and Summit II. In this video, Steele described the concept of stereotype threat and discusses his findings in stereotype threat-related research. After viewing the video, they responded to four "true" or "false" statements (see Appendix I) to verify their understanding of the concept of stereotype threat. Once all participants completed these statements, the experimenter verified that all participants answered the statements correctly. Participants were told that "it's important to keep in mind that if you are feeling anxious while taking the test, this anxiety could be the result of negative stereotypes that are widely known in society and have nothing to do with your actual ability to do well on the test"' (Johns et al., 2005, p. 176). Once the experimenter confirmed that all participants understood the correct answers to the questions about the video, they proceeded to take the math test, the Causal Dimension Scale II, the General Self-Efficacy Scale, The Perceived Faculty Support Scale, and the demographic survey.

Participants in the stereotype threat condition were told that they were participating in the study in order to examine gender differences in math performance on this test (see Appendix K). They were also told that this test had 
previously been found to demonstrate which women will succeed in the fields of math and science and that University of Rhode Island would like to examine which women enrolled in these programs will be successful. They were told that during past administrations of this test, women have performed significantly worse than men and the researcher is conducting this study in order to examine if University of Rhode Island women students will also perform worse than men. Once they were provided with this explanation, all participants completed the math test, the Causal Dimension Scale II, the General Self-Efficacy Scale, the Perceived Faculty Support Scale, and the demographic survey.

After participants from both the teaching intervention and the stereotype threat group were debriefed, they were provided with instructions for logging into the online survey program called "Survey Monkey" one week after the day they completed the aforementioned parts of the study. They were informed that they would receive an e-mail to remind them of the day they could log into Survey Monkey and would be provided the link to the website in this e-mail. Participants were reminded that they would be eligible to win $\$ 100$ in a raffle if they completed the questions on Survey Monkey. When participants logged into Survey Monkey, they were asked to answer the four questions that the participants of the teaching intervention condition answered after watching the Claude Steele video (see Appendix I).

Data Analysis

Results examining Hypothesis 1 and 2 of this study were analyzed using Multivariate Analysis of Covariance (MANCOVA), followed by individual 
follow-up ANCOVAs. The independent variable was the experimental condition (teaching intervention or stereotype threat condition). The five dependent variables were the score on the math test, and the subtest scores on the CDS II (for the following four factors: locus of causality, stability, personal control, and external control). The math test score was calculated by taking the total amount of correct responses and dividing them by the total amount of problems attempted. The number of years in their academic program was used as a covariate in order to control for individual differences in mathematics skill level (Steele \& Aronson, 1995). The data from this study was analyzed using the statistical program SPSS. Hypothesis 3 was analyzed by comparing the amount of correct responses obtained by the participants in the teaching intervention condition with those in the stereotype threat condition. Between-group differences were analyzed using ANOVA with SPSS. The analysis performed in Hypothesis 4 was performed using Simultaneous Multiple Regression with SPSS.

\section{Results}

In order to verify that there were not differences between groups based upon their year in college, discipline of study, participation in an academic group, the number of math classes they have completed, and their SAT scores, preliminary analyses were performed. A Chi-Square was performed in order to examine if there were differences between groups due to their year in school (i.e., freshman, sophomore, junior, senior). No significant differences were found, $\chi^{2}$ $(1, N=114)=0.13, p>.05$. No significant differences were found between groups based on their discipline of study (STEM or non-STEM, which refers to 
science, technology, engineering, and technology), $\chi^{2}(1, N=38)=0.21, p>.05$.

There were no significant differences based upon whether or not they belonged to an academic club or lived in an housing environment that supported their studies, $\chi^{2}(1, N=76)=0.99, p>.05$. Analysis of Variance (ANOVA) was performed in order to determine whether or not there were differences between groups based upon the number of math classes they completed. There were no differences found between groups, $F(2,97)=.96, \mathrm{p}>.05$. An ANOVA was also performed in order to examine whether or not there were differences between groups based upon the SAT scores earned by participants. No significant differences were found, $F(26,73)=.93, \mathrm{p}>.05$.

Multivariate analysis of covariance (MANCOVA) was performed to investigate differences in the math test performance of females in the stereotype threat intervention condition as well as the stereotype threat condition. The study also examined the attributions made by participants for their success (or failure) on the math test. The independent variables were test condition (stereotype threat intervention condition and stereotype threat condition). Seven dependent variables were used: performance on the math test, external control, personal control, locus of causality, stability, self-efficacy, and perceived faculty support. Preliminary assumption testing was conducted to check for normality, linearity, and homogeneity of variance with no serious violations noted.

Hypothesis 1: When women participants are informed about the concepts and dangers of stereotype threat by viewing a video of Claude Steele speaking about stereotype threat theory and research (Teaching Intervention condition), 
they will perform better on a math test than women in another group: Those who are told the results of their math test will be compared with that of men (Stereotype Threat condition).

There were no significant differences found between the groups: $F(7,91)$ $=.45, \mathrm{p}=.87$, partial eta squared $=.03$ and Wilks' Lambda $=.97$. This analysis demonstrates that differences existed between the groups, but they were not statistically significant. Teaching participants about stereotype threat by showing them a video of Claude Steele discussing the theory and research did not provide a buffer which allowed participants to perform significantly better than those who did not receive this description. The results of this study did not support Hypothesis 1.

Hypothesis 2: When women participants are informed about the concepts and dangers of stereotype threat (by viewing a video of Claude Steele speaking about his research), they will make more internal attributions for their success on the test (and participants will obtain higher scores on the Causal Dimension Scale II (McAuley, et al, 1992) on three factors: locus of causality, stability, and personal control). When women are not informed about the concepts and dangers of stereotype threat, they will be more likely to believe that their failure is due to internal attributions (participants will obtain lower scores on the external control factor of the Causal Dimension Scale 1I).

When the two groups were compared, no significant differences were found: $F(4,95)=.40, \mathrm{p}=.30$, partial eta squared $=.013$ and Wilks' Lambda $=$ 99. In Hypothesis 2, the researcher stated that she expected to see the two groups 
make different attributions for their performance, however, there were no significant differences found between groups. These results suggest that when females learn about stereotype threat by watching a short video, they do not make different causal attributions for their performance on a math test.

Hypothesis 3: When participants are taught about the concept and dangers of stereotype threat by watching a video of Claude Steele presenting his theory, they will be more likely to retain the central message than participants who are provided with a description of stereotype threat in a written debriefing statement. Participants in the Teaching Intervention condition are expected to achieve an average of $60 \%$ of the questions correct one week after participating in the study (Moseley, et al., 2006). This particular score estimate is chosen in order to demonstrate that the expected difference is greater than chance.

This study examined the extent to which the core concepts of stereotype threat could be retained one week after being exposed to the message. Results found that participants obtained at least $60 \%$ of the questions correct. The mean score of the teaching intervention group was $3.08(\mathrm{M}=3.08, \mathrm{SD}=1.13)$. This mean score demonstrates that the teaching intervention group obtained an average of $77 \%$ correct responses in comparison to the stereotype threat group who obtained an average of $63 \%$ correct.

Hypothesis 4: Based on previous theory and empirical research on perceived faculty support (e.g., Nesbitt-Shelton, 2000; Vogt et al., 2007), selfefficacy (e.g., Pajares, 1996; Pintrich \& DeGroot, 1990; Zimmerman, et al, 1996), and counteracting stereotype threat (Johns et al., 2005), the following 
hypotheses are made:

4A: There will be a positive correlation between perceived faculty support and math test scores; Perceived faculty support will predict performance on the math test.

Linear regression was used to assess the ability of the variable perceived faculty support to predict performance on the math test. The total variance explained by the model as a whole was 0.00 (no variance was explained by the model), $F(1,98)=.10, \mathrm{p}=.90$. For every unit increase in perceived faculty support, there is a corresponding decrease in math test score of .01. Perceived faculty support did not predict math test performance.

4B: There will be a positive correlation between self-efficacy and math test scores; Self-efficacy will predict math test performance on the math test.

Linear regression was used to assess the ability of the variable SelfEfficacy to predict performance on the math test. The total variance explained by the model as a whole was 0.00 (no variance was explained by the model), $F(1$, $98)=.11, p=.92$. For every unit increase in self-efficacy, there was a corresponding decrease in math test score of .03 . Self-efficacy did not predict math test performance.

4C: There will be a positive correlation between treatment condition (teaching intervention) and math test scores; Treatment condition will predict math test performance on the math test. 
Linear regression was used to assess the ability of the variable treatment condition to predict performance on the math test. The total variance explained by the model as a whole was 0.001 (virtually no variance was explained by the model), $F(1,98)=.21, \mathrm{p}=.99$. Treatment condition did not predict math test performance.

4D: There will be a positive correlation between the interactions between selfefficacy and perceived faculty support; This interaction will predict math test performance.

Multiple regression was used to assess the ability of the variables selfefficacy, perceived faculty support, and the interaction of these variables to predict performance on the math test. The interaction of these variables did not predict math test performance as $2.8 \%$ of the variance was explained by the model (Adjusted $R$ Squared $=.028), F(3,96)=.09, \mathrm{p}=.97$. Self-efficacy and perceived faculty support did not predict math test performance.

4E: There will be a positive correlation between the interaction of self-efficacy and internal attributions; This interaction will predict performance on the math test.

Multiple regression was also used to assess the ability of the interaction of variables self-efficacy and internal attributions to predict math test performance. This predictor model accounted for $2.3 \%$ of the variance in math test performance, $F(3,96)=.268, \mathrm{p}=.849$, Adjusted $R$ Squared $=-.02$. Self-efficacy and internal attributions did not predict math test performance. 
Upon completing the study, analyses were performed in order to verify that the math test results of the participants could not be predicted based upon the participants' year in college, discipline of study, participation in an academic group, the number of math classes they have completed, and their SAT scores. Regression analysis demonstrated that the year in school of participants also did not predict math test performance, $F(1,98)=.08, \mathrm{p}=.78$, Adjusted $R$ Squared $=$ .09. Results showed that having a STEM (versus non-STEM) major did not predict math test performance, $F(1,98)=.91, \mathrm{p}=.17$, Adjusted $R$ Squared $=$ .009 . Belonging to an academic club or living in a student residence that supports academics did not predict math test performance, $F(1,98)=.09, \mathrm{p}=.89$, Adjusted R Squared $=.01$. The number of math classes completed by participants did not predict math test performance, $F(1,98)=.06, \mathrm{p}=.85$, Adjusted $R$ Squared $=.01$. SAT scores earned by participants did not predict math test performance, $F(1,98)=.22, \mathrm{p}=.88$, Adjusted $R$ Squared $=.01$.

\section{Discussion}

The present study sought to examine the effectiveness of an intervention designed to shield females from the potentially harmful effects of stereotype threat. Participants were provided with a description of stereotype threat and warned to heed caution to the performance hindering effects associated with it. After being provided with this explanation, participants completed a math test. The math test results of these participants were compared to those of participants who had not been provided with information related to stereotype treat. The present findings demonstrate that the participants who were provided with this 
information performed better on the math test than those who were not given the stereotype threat information. However, the difference between these groups was not statistically significant. As was mentioned earlier, there are researchers who criticize stereotype threat research. While the current study may bolster their argument, there are several explanations that may explain why this study did not produce statistically significant results.

The intervention used in the current study was modeled after the intervention created by Johns et al. (2005). Johns and colleagues found significant differences in math test performance between participants in the intervention condition and those in the stereotype threat condition. In comparing the current study to that of Johns, there are several reasons that explain why significant differences were not produced in the present investigation. First, Johns taught participants about stereotype threat by providing them with a description of the concept. This description was not published with the study, so we don't know exactly what message was conveyed. $1 \mathrm{t}$ is possible that the message and the language used might have been significantly different than the one used in the current study. Second, Johns used both a male and a female experimenter. As the current study was run by only a female experimenter, it is possible that participants were not as adversely affected by stereotype threat effects. Consequently, group differences were less likely to be found if the stereotype threat group was not as negatively impacted as the group used in Johns' study (that used a male experimenter). Finally, the study by Johns included students who were studying statistics. The current study included participants from a 
variety of different fields. As math was not the core area of study for all the participants in the current study, it is possible that they didn't have the same stereotype threat experience as the participants in Johns' study.

A second purpose of this experiment was to examine potential differences between groups when participants in the teaching intervention condition were directed to make external attributions for any anxiety experienced during testing. Participants completed the CDS II, a scale which measures the attributions one makes for a success or failure on a task. It was hypothesized that when female participants were taught about the concept and dangers of stereotype threat, they would obtain higher scores on the CDS II than female participants who were led to believe that their performance would be compared to male performance on three factors: locus of causality, stability, and personal control. It was predicted that female participants who were taught about stereotype threat would obtain lower scores on the external control factor than the females who believed their performance would be compared to that of the males. This study did not demonstrate significant differences between groups on any of the four dimensions.

Apart from Frost (2007), previous research has not looked at differential patterns of causal attributions in stereotype threat and non-stereotype threat situations. Several stereotype threat studies examined the effect of asking participants to attribute potential failure to an external source (Brown \& Josephs, 1999; Good et al., 2003; Wilson \& Linville, 1985) however these studies did not measure attributions in the same fashion as the current study. Causal attribution 
theory suggests that when individuals are made to doubt their ability in a domain, they may attribute their performance to an internal source such as lack of ability. This suggests that participants in the stereotype threat condition would do the same. However, non-significant results in Frost (2007) and in the present study imply that perhaps differences do not exist in the way in which individuals attribute their performance in stereotype threat and non-stereotype threat situations. While attributing potential failure to an external source buffers stereotype threats from occurring, there appear to be no differences in the way females in stereotype threat and non-stereotype threat situations attribute their performance on math tasks.

A third purpose of the study was to examine if participants were able to recall the message taught to them about stereotype threat one week after participating in the study. The present study found that participants obtained an average of $77 \%$ of the answers correct. This is an important finding for future stereotype threat research that may look at how teaching individuals about stereotype threat might generalize to other situations.

Prior research has not examined if participants in a stereotype threat intervention study are able to recall the intervention message after completing the study. However, Craik and Tulving (1975) conducted a study examining how much information individuals retain one week later after learning new information during the study. Results showed that when participants were given the opportunity to gain understanding of the material during the study, they would remember more information than the participants who were merely exposed to the 
material and not provided with an opportunity to gain understanding. Craik and Tulving found that participants were able to obtain an average of $60 \%$ correct on a four questions quiz measuring message retention. The current study found that participants who were taught about stereotype threat by watching the Clause Steele video obtained an even higher average of correct responses $(77 \%)$. The results of the current study are in keeping with that of Craik and Tulving. Although the intervention group obtained higher scores on the follow-up questions than the stereotype threat group, the stereotype threat group obtained high scores as well. It is possible that this is due to the fact that the debriefing experience might have been powerful and salient to the participants, as they might have been considering the purpose of the study throughout the duration of it. Once they learned of the "true" purpose, this may have remained salient in their memory.

A fourth purpose of this study was to examine if the participants' sense of perceived faculty support would predict their performance on the math test. It was hypothesized that participants with a greater sense of perceived faculty support would perform better on the math test. This hypothesis is based on the idea that when individuals feel that they are supported by their academic departments and faculty, this will positively influence their academic performance. Results of this study found that perceived faculty support did not predict math test performance.

In a study conducted by Nesbitt-Shelton (2000), she found that when participants had higher levels of perceived faculty support, they were more likely to complete the degree they were pursuing, and also more likely to have a higher 
GPA. Although Nesbitt-Shelton found there to be a relationship between perceived faculty support and academic success, there is a major difference between the study she conducted and the current study. Nesbitt-Shelton measured overall GPA of the participants in her study. As the current study only measured performance on one test, this may explain why perceived faculty support was not predictive of math test performance. Performance on a single test does not measure academic competency as well as one's overall GPA, which is composed of myriad forms of assessment over a wide range of materials. Secondly, NesbittShelton's study only included nursing students in her pool of participants. As the current study included students from a variety of majors, it is possible that perceived faculty support might have been predictive for students in some majors but not others. This may have contributed to an overall non-significant effect.

A fifth purpose of the study was to examine if the participant's level of general self-efficacy would be predictive of math test performance. It was hypothesized that participants who had a higher level of self-efficacy would obtain higher scores on the math test. This hypothesis was based on the idea that when individuals believe that they are able to perform well on a task, they will be more likely to succeed on said task. Results of the study found that self-efficacy scores were not predictive of math test performance. Vogt et al. (2007) found that one's level of self-efficacy was the strongest determinant for a high GPA. As Vogt was measuring academic performance as an average of overall performance (GPA), it is possible that self-efficacy may correlate with one's overall performance, yet not necessarily performance on one task. The current study 
measured academic performance by asking participants to complete one math test. Perhaps it is important to look at performance in a broader context if we expect to find a relationship between academic performance and self-efficacy.

A sixth purpose of this study was examining whether the factors of selfefficacy and perceived faculty support would predict performance on a math test. While self-efficacy has previously been examined in stereotype threat research, perceived faculty support has not been considered. Results of the present study did not show that the interaction of these two variables were predictive of math test performance.

Vogt et al. (2007) examined self-efficacy, perceived discrimination, and GPAs in a population of female engineering students. These researchers found that there was a negative relationship between self-efficacy and perceived discrimination. Students who felt they experienced a greater amount of discrimination in their academic department also had lower levels of self-efficacy. Vogt also found that self-efficacy was positively related to GPA in that students with lower levels of self-efficacy also reported lower GPAs. Based on the results of Vogt, the current study hypothesized that students with higher levels of selfefficacy and perceived faculty support would perform better on the math test. The current study did not find that perceived faculty support and self-efficacy were predictive of math test scores. It is possible that non-significant results were found in the current study due to the fact that participants in the current study represented a variety of different academic departments. Some of the students may come from departments that provide greater support and consequently foster 
higher levels of self-efficacy. The variety of departments represented in the current study may not have similar patterns of support, which would result in different patterns of self-efficacy and explain the lack of significant findings.

The final purpose of this study was to examine if the interaction of the variables of self-efficacy and internal attributions would be predictive of math test performance. The interaction of these variables has not been looked at in previous stereotype threat research. The results of this study did not find that the interaction of these variables predicted math test performance. Shunk and Gunn (1986) found that there was a relationship between internal causal attributions and self-efficacy. However, a difference between this study and the current study is that Shunk and Gunn worked with participants during four different time periods over several consecutive days. If the current study had worked with participants several times, it is possible that the message of stereotype threat might have become more salient. If this message was more salient, then their ratings of causal attributions and self-efficacy might have also been different.

\section{Limitations}

This study had a number of limitations. One limitation concerns the limited exposure to stereotype threat received by the participants. If individuals were to participate in a series of training workshops, it is possible that the effects of the training might have greater impact on math test performance. Previous stereotype threat research has not examined the impact of more extensive exposure. This study may be considered a first step in this area of research as it is 
the only known study to examine whether or not participants can retain the message.

A second limitation to this study is the fact that the participants were recruited from a variety of different departments. Although participants were recruited from majors that emphasized math skills, it seems possible that there is a great deal of variability in the structure of the different departments from which the participants were recruited. Some of the departments may offer a much more supportive environment for their students than others, which may consequently affect the way in which the participants rated their levels of self-efficacy and perceived faculty support. However, if future studies were to compare individual departments that have low enrollment of female students (such as some math and engineering departments) and also place great importance on math skills, we may examine issues specific to these departments while also making comparisons of one department to the other. Including participants from a variety of different departments may confound issues and may contribute to the lack of significant findings.

Another possible limitation concerns the fact that the experimenter was a female, as participants may have been positively impacted by the female presence. Many of these students are previously taught by male professors. Being asked to complete a math task by a female experimenter may have impeded stereotype threat effects from surfacing in the stereotype threat condition, consequently resulting in a lack of differences between groups. Had equal numbers of participants been assigned to conditions run by a male and female 
experimenter, the effect of experimenter gender on condition may have been controlled. The study conducted by Johns et al. (2005) ran groups by equal numbers of male and female experimenters. As the results of Johns' study showed significant differences, the fact that the current study only used a female experimenter may explain the lack of significant differences between groups.

Limited power and reliability may also be a limitation in this study. When power is limited, one is less able to reject a false null hypothesis. As the sample size of the study was not very large, using an insufficient amount of participants may have impacted the power of the study. The study produced limited to small effects, therefore, the effect size may have impacted the power of the study.

A final limitation of this study is the fact that participants completed the experiment in the company of their female peers. Many of these students come from male-dominant departments where many of their classes are male majority. Participating in the study with a group of females may have empowered the participants to all perform their best (regardless of the condition) and also may have prompted them to evaluate their levels of self-efficacy and faculty support more highly.

Future Research Directions

This study found that participants were able to retain the core concepts of stereotype threat in their memory one week after being exposed to it. Although this was admittedly a cursory examination of knowledge retention, it may be considered a first step in the development of a curriculum that takes place during more than one sitting. Future research should examine the long-term effectiveness 
of a series or teaching sessions (or workshops) on stereotype threat-related issues. If the effects of these workshops are measured long-term, then it will be possible to assess whether or not this exposure will influence a greater number of females to pursue studies in these fields.

Understanding that women perform worse on math tasks in a single sitting or that they perform better on certain tasks after being exposed to an intervention in a single sitting is only the beginning. It is more important that we consider the greater significance and potential impact of this information. Researchers need to reconsider why stereotype threat research is being conducted. Thus far, research in this domain has demonstrated that performance differences exist between groups when individuals are made to think about the stereotype regarding their ability in said domain. Researchers have also demonstrated that there are a number of interventions that protect participants from the effects of stereotype threat taking place. Now we must focus on moving towards the next phase of stereotype threat research: using our knowledge to prevent disidentification from taking place and also supporting females in their pursuit of careers in math and science fields. 
Appendix A

\section{Diagnostic Math Exam}

Instructions: Please fill in the following information. Print clearly.

Date:
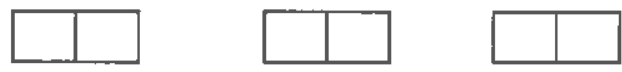

Month

Day

Major:

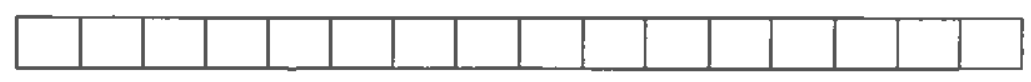

*The contents of this test are confidential. Disclosure or reproduction of any portion of it is prohibited.

\section{DO NOT OPEN THE TEST BOOKLET UNTIL INSTRUCTED TO DO SO.}

\section{THIS EXAM BOOKLET MUST NOT BE TAKEN FROM THE ROOM.}

Registered® 1999 by Massachusetts Aptitude Assessment Center. All rights reserved. 


\section{Appendix B}

How well do you think you performed on the math test?

What caused you to perform well (or poorly)?

Think about your responses above. The items below concem your opinions about the causes of your performance on the math test you just completed. Circle one number tor each of the following questions. PLEASE NOTE: IF YOU FEEL THE STATEMENT ON THE LEFT MORE CLOSELY RESEMBLES YOU, YOU WILL CHOOSE A LOWER NUMBER (I.E., "1," "2," "3." IF YOU FEEL THE STAEMENT ON THE RIGHT MORE ACCURATELY DESCRIBES YOU, YOU WILL CHOOSE A HIGHER NUMBER (I.E., "7," "8," 9").

Do you feel the cause of your performance is something:

1. That reflects an aspect of the situation

2. Not manageable by you

3. Temporary

4. You cannot regulate

5. Over which others have no control

6. Outside of you

7. Variable over time

8. Not under the power of other people

9. Something about others

10. Over which you have no power

11. Changeable

12. Other people cannot regulate

$\begin{array}{llllllllll}1 & 2 & 3 & 4 & 5 & 6 & 7 & 8 & 9 & \text { That reflects an aspect of yourself } \\ 1 & 2 & 3 & 4 & 5 & 6 & 7 & 8 & 9 & \text { Manageable by you } \\ 1 & 2 & 3 & 4 & 5 & 6 & 7 & 8 & 9 & \text { Permanent } \\ 1 & 2 & 3 & 4 & 5 & 6 & 7 & 8 & 9 & \text { You can regulate } \\ 1 & 2 & 3 & 4 & 5 & 6 & 7 & 8 & 9 & \text { Over which others have control } \\ 1 & 2 & 3 & 4 & 5 & 6 & 7 & 8 & 9 & \text { Inside of you } \\ 1 & 2 & 3 & 4 & 5 & 6 & 7 & 8 & 9 & \text { Stable over time } \\ 1 & 2 & 3 & 4 & 5 & 6 & 7 & 8 & 9 & \text { Under the power of other people } \\ 1 & 2 & 3 & 4 & 5 & 6 & 7 & 8 & 9 & \text { Something about you } \\ 1 & 2 & 3 & 4 & 5 & 6 & 7 & 8 & 9 & \text { Over which you have power } \\ 1 & 2 & 3 & 4 & 5 & 6 & 7 & 8 & 9 & \text { Unchangeable } \\ 1 & 2 & 3 & 4 & 5 & 6 & 7 & 8 & 9 & \text { Other people can regulate }\end{array}$

McAuley, E., Duncan, T. E., \& Russell, D. W. (1992). Measuring causal attributions: the revised causal dimension scale (CDS-II). Personality and Social Psychology Bulletin, 18(5), 566-573. 
Appendix C

Instructions: Please choose the number that corresponds to each statement. Place your answer in the box in front of each statement.

$1=$ Not at all true 2 = Hardly true 3 = Moderately true $4=$ Exactly true

\begin{tabular}{|l|l|}
\hline & $\begin{array}{l}\text { 1. I can always manage to solve difficult problems if I try hard } \\
\text { enough. }\end{array}$ \\
\hline & $\begin{array}{l}\text { 2. If someone opposes me, I can find the means and ways to get } \\
\text { what I want. }\end{array}$ \\
\hline & $\begin{array}{l}\text { 3. It is easy for me to stick to my aims and accomplish my goals. } \\
\text { events. }\end{array}$ \\
\hline & $\begin{array}{l}\text { 5. Thanks to my resourcefulness, I know how to handle unforeseen } \\
\text { situations. }\end{array}$ \\
\hline & $\begin{array}{l}\text { 6. I can solve most problems if I invest the necessary effort. } \\
\text { my coping abilities. }\end{array}$ \\
\hline $\begin{array}{l}\text { 8. When I am confronted with a problem, I can usually find } \\
\text { several solutions. }\end{array}$ \\
\hline \begin{tabular}{l} 
9. If I am in trouble, I can usually think of a solution. \\
\hline
\end{tabular} \\
\hline
\end{tabular}

Schwarzer. R., \& Jerusalem, M. (1995). Generalized Self-Efficacy Scale. In J.

Weinman, S. Wright, \& M. Johnston (Eds.), Measures in health psychology: A user's portfolio. Causal and control beliefs (pp. 35-37). Windsor, UK. 


\section{Appendix D}

\section{PERCEIVED FACULTY SUPPORT}

Think about your faculty adviser within your major. Indicate how strongly you agree or disagree with each of the following statements by circling the appropriate number. Higher numbers indicate greater agreement and lower numbers indicate greater disagreement.

\section{Most faculty members within your major:}

1. Know if students understand what is being taught

\section{Strongly}

2. Demonstrate respect for students

3. Set challenging but attainable goals for students

4. Acknowledge when students have done well

5. Are helpful in new situations without taking over

6. Stress important concepts

7. Are approachable

8. Correct students without belittling them

9. Listen to students

10. Can be trusted

11. Give helpful feedback on student assignments

12. Are open to different points of view

13. Encourage students to ask questions

14. Provide assistance outside of class

15. Vary teaching methods to meet student needs

16. Make expectations clear

17. Are patient with students

18. Are good role models for students

\section{Disagree}

$\begin{array}{lllllll}1 & 2 & 3 & 4 & 5 & 6\end{array}$

\section{Strongly}

\section{Agree}

$\begin{array}{lllllll}1 & 2 & 3 & 4 & 5 & 6 & 7 \\ 1 & 2 & 3 & 4 & 5 & 6 & 7\end{array}$

$\begin{array}{lllllll}1 & 2 & 3 & 4 & 5 & 6 & 7 \\ 1 & 2 & 3 & 4 & 5 & 6 & 7 \\ 1 & 2 & 3 & 4 & 5 & 6 & 7 \\ 1 & 2 & 3 & 4 & 5 & 6 & 7 \\ 1 & 2 & 3 & 4 & 5 & 6 & 7 \\ 1 & 2 & 3 & 4 & 5 & 6 & 7 \\ 1 & 2 & 3 & 4 & 5 & 6 & 7 \\ 1 & 2 & 3 & 4 & 5 & 6 & 7 \\ 1 & 2 & 3 & 4 & 5 & 6 & 7 \\ 1 & 2 & 3 & 4 & 5 & 6 & 7 \\ 1 & 2 & 3 & 4 & 5 & 6 & 7 \\ 1 & 2 & 3 & 4 & 5 & 6 & 7 \\ 1 & 2 & 3 & 4 & 5 & 6 & 7 \\ 1 & 2 & 3 & 4 & 5 & 6 & 7 \\ 1 & 2 & 3 & 4 & 5 & 6 & 7\end{array}$


19. Are realistic in expectations

$\begin{array}{lllllll}1 & 2 & 3 & 4 & 5 & 6 & 7 \\ 1 & 2 & 3 & 4 & 5 & 6 & 7 \\ 1 & 2 & 3 & 4 & 5 & 6 & 7 \\ 1 & 2 & 3 & 4 & 5 & 6 & 7\end{array}$

23. Provide study guides and written materials

$\begin{array}{lllllll}1 & 2 & 3 & 4 & 5 & 6 & 7\end{array}$

24. Demonstrate confidence in students

$\begin{array}{lllllll}1 & 2 & 3 & 4 & 5 & 6 & 7\end{array}$

Nesbitt-Shelton, E. (2003). Faculty support and student retention. Journal o Nursing Education, 42(2), 68-76. 


\section{Appendix E}

\section{Personal Background Questions}

Instructions: Please provide the following information:

1) What is your major? (please print)

2) What year in school are you?

3) SAT Quantitative score (if you do not remember your exact score, please estimate. It is extremely important that you do not exaggerate your SAT score. This will negatively affect the results of this study).

4) Which of the following math classes have you successfully completed? (place a check next to those you have completed)

Algebra
Geometry
Advanced Algebra
Trigonometry
Calculus
Advanced Calculus

5) With which racial/ ethnic group do you self-identify? (check one) American Indian or Alaska Native Asian American Black/ African American Native Hawaiian/ Other Pacific Islander White/ European American Hispanic/ Latino(a) Other race/ ethnicity (please specify

here)

\begin{tabular}{l} 
American Indian or Alaska Native \\
Asian American \\
Black/ African American \\
Native Hawaiian/ Other Pacific Islander \\
White/ European American \\
Hispanic/ Latino(a) \\
Other race/ ethnicity (please specify \\
\hline
\end{tabular}

6) What year in school are you? Freshman Sophomore Junior Senior

Please remember to respond to the four questions on Survey Monkey in one week. You will receive instructions before you leave explaining how to do this. If you answer these questions on Survey Monkey, you will be eligible to win $\$ 100$ ! 


\section{Appendix F}

Recruitment Statement:

I am Megan Frost, a doctoral student in Psychology, and I am carrying out my dissertation examining how people perform on math tests. The study involves completing 5 scales, and takes about 25 minutes to complete. I would really appreciate your help taking part in the study. I have a schedule of times to participate and wondered if you would like to sign up for one of them, or if an alternative time would be more convenient. If you participate in this study, your name will be placed in a raffle making you eligible to win $\$ 100$. In order to be eligible to win the money, you must complete the study in its entirety. If you have any questions, please contact me at aixwaters@hotmail.com.

If you are interested in participating, please provide the following information:

Name

Major

E-mail address

I am available on the following days and times:

Date 1 , Time 1

Date 2, Time 2

Date 3, Time 3

Date 4, Time 4

I am not available any of those days but I am available on these days and time: 


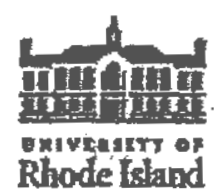

Appendix G

University of Rhode Island

Department of Psychology

Chafee Building

Kingston, RI 02881

Telephone: 401.874 .2193

\section{Informed Consent}

You are being äsked to take part in a research project in which you will complete a math test and answer some questions about college student math performance. You don't have to like or be good at math to take part. This project will be explained to you in detail by the researcher. If you have any questions, please feel free to ask them If you have any questions that you would like to ask after you complete the experiment, Megen:Frost, the principal researcher of this study, (617.838.8474) will be available to discuss them with you later. You must be at least 18 years to participate in this research study.

Description of the project

We would like you to participate in a research study titled "Math Performance Among University of Rhode Istand Students." The puifose of this study is to gain a better understanding of stident math performance.

What will be done:

If you complete this study, you will complete a math test. After completing the math test, you will complete a few questionnaires,

Risks or discomfort:

If you choose to participate in this study, you may experience some mild psychological discomfort.

Some research designs require that the full intent of the study not be explained prior to participation. Although we have described the general nature of the tasks that you will be asked to perform, the full intent of the study will not be explained to you until after the completion of the study. At that time, we will provide you with a full debriefing which will include an explanation of the hypothesis that was tested and other relevant background information pertaining to the study. You will also be given an opportunity to ask questions you have about the hypothesis and procedures used in the study.

Benefits of this study:

In participating in this study, you will have an opportunity to learn about the math performance of University of Rhode Island students.

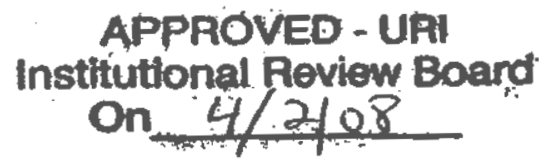




\section{Appendix $\mathrm{H}$}

Transcription of Instructions for the Teaching Intervention Condition

Thank-you for coming today to participate in this study. You have a piece of paper in front of you called an "informed consent" form. Please read through it thoroughly before we proceed.

(Pause while all participants read the informed consent form).

Has everyone finished? Do any of you have any questions?

Today you are going to watch a video that will last seven minutes. This video shows Claude Steele, an esteemed researcher from Stanford University, speaking about his research at a convention of the Multicultural Summit Conference. Please try and pay attention to what Steele is saying in the video, as you will be asked to respond to several questions after the video.

(Video will begin and be shown for seven minutes).

Ok, now that the video has finished, I will pass each of you a packet of materials. The top page has four questions about the video. You may respond to these questions as soon as you receive the packet.

(Participants respond to the four questions).

We will now go over the answers. What is the answer to number one? (Verify correct answer - the experimenter will explain the correct answer if participants do not understand.) The same will be done for questions two through four.

(Pause while packets and pencils are being handed out).

Next you will be completing a standardized math test. You will be completing this test in order for us to examine gender differences in mathematics ability. You will be provided with 15 minutes to complete the test. I will let you know when you should stop working on the test.

Please remember what you learned in the video: Women in a stereotype threat situation sometimes experience anxiety that causes them to perform worse on a math task (pause). We would like you to attribute any anxiety you might experience during the math test to stereotype threat (pause). Do not attribute this anxiety to a lack of ability to perform well on the test (pause). Please start the math test. 
(Participants complete the math test).

Alright, everyone put your pencils down. In the last few pages of the packet, you will find a few short surveys. Please complete the surveys in their entirety. If you are uncertain of a response, please estimate a response. Please remain seated until you

are instructed to leave.

Provide participants with time to complete the surveys. When everyone has completed the surveys, the surveys will be collected).

Thank you all for your participation! Remember to answer the four questions on Survey Monkey one week from today in order to be eligible to win $\$ 100$ in the raffle!

Debriefing instructions follow in Appendix L. 


\section{Appendix I}

Instructions: Please answer the following four questions, by choosing True or False, about the video you just watched.

1. Stereotype Threat refers to being in a situation where you are asked to perform a task for which negative stereotypes exist for your group on that task.

True False

2. Claude Steele's research studies have found that women perform worse than men on math tasks when they are made to think about the negative stereotype regarding women's math ability. True False

3. According to Claude Steele, if you are someone who cares about doing well in a subject for which the group you belong to has negative stereotypes, you may decide to stop trying to do well in this subject when you are exposed to the negative stereotype. True False

4. Claude Steele's research found that minority students who attended selective schools or universities and had high SAT scores were affected by Stereotype Threat. True False 
May 3, 2006

\author{
Megen Frost \\ University of Rhode Island \\ 196 Wayland Avenue \#1 \\ Providence, RI 02906 \\ Dear Ms, Frost:
}

Thank you for your request to use ETS's copyrighted GREO kest materials. it is.oir understanding that you will be using these materials as part of your undergraduate research at the Univisity of Rhode Island.

Educational Testing Service is pleased to grant royalty-froe, nonexclusive, nontransferable permission to reproduce the test materials listed in the attached Appendix A. The following terms apply. to this permission:

1. The test material is to be used only for the research puposies described in your letter and is not to be distributed, published, or used in any other manner without written permission from ETS.

2 Please use the following credit line following the coince gitution on the page where you use the material andor other mpipopriate location:.

GRB test materials selected from GRE Practicing to Talo the General Test, $9^{\text {t }}$ Edition, 1994, Educational Testing Service. Reprimted by permission of Educetional Testing Service, the copyright owner:

3. The test materials must be placted in an ippendix to the distertation, and the appendix. must not be made avilable to Univerrity Miciofilms, Ine.

4. You will assume responsibility for the analyses and conclwoicns of your stivdy and, other than acknowledgment of the source of the questions, you will not use ETS's name in ach a why as to imply participation in ix responsibility for your rescaich.

5. If you are referencing ETS's GREQ trademirk in your disscrtation and/or publication, specific guidelines for the informitional use of the GRE trademark must be followed. Please review the Guideline for the Proper Informational Use of ETS Thademarts in the attached Appendix B. 


\section{Appendix K}

Transcription of Instructions for the Stereotype Threat Condition

Thank-you for coming today to participate in this study. You have a piece of paper in front of you called an "informed consent" form. Please read through it thoroughly before we proceed.

(Pause while all participants read the informed consent form).

Has everyone finished? Do any of you have any questions?

I will now provide you with a packet of papers and a pencil. Please wait to open the packet until you are instructed to do so.

(Pause while packets and pencils are being handed out).

Today you will be completing a standardized math test. You will be completing this test in order for us to examine gender differences in mathematics ability. You will be provided with 15 minutes to complete the test. We will let you know when you should stop working on the test. This test has previously been found to demonstrate which women will succeed in the fields of math and science. URI would like to examine which women enrolled in these programs will be successful. During past administrations of this test, females have performed significantly worse than men. The researcher is conducting this study in order to examine if University of Rhode Island women students will also perform worse than men.

(Participants complete the math test).

Alright, everyone put your pencils down. In the last few pages of the packet, you will find a few short surveys. Please complete the surveys in their entirety. If you are uncertain of a response, please estimate a response. Please remain seated until everyone has finished and you are instructed to leave.

(Provide participants with time to complete the surveys. When everyone has completed the surveys, they will be collected).

Thank you all for your participation! Remember to answer the four questions on Survey Monkey one week from today in order to be eligible to win $\$ 100$ in the raffle!

Debriefing instructions follow in Appendix L. 
Debriefing Statement

\section{Appendix L}

Thank you for participating in this study. FIRSTLY, RESEARCH HAS SHOWN THAT THERE ARE NO DIFFERENCES IN MALE AND FEMALE MATH ABILITY. This study is examining an intervention to allow females to perform to their natural ability when in stereotype threat situations. Stereotype threat is a phenomenon that takes place when there are negative stereotypes about a group's performance on a specific task. Research about stereotype threat shows that women and minorities may underperform on math and intellectual tests when stereotypes about math or intellectual abilities are highlighted. For example, when females are told that a math test that they are about to take has shown gender differences in the past, (i.e., males performing better than females) the females perform significantly worse than the males. However, when participants were told that there were no gender differences in the performance on the test, men and women performed equally well. Studies have found that when elderly participants are told that they generally perform worse on memory tasks, these participants perform worse than when they are provided with a statement about typical performance. Some studies have found that when Asian participants are made to think about their Asian identity before taking a math test, they perform better than when they are made to think about their female gender identity. This study is examining a method for improving female performance while in a stereotype threat situation. Do you have any questions? Again, thank you very much for your participation. 


\section{Bibliography}

Alden, L. (1986). Self-efficacy and causal attributions for social feedback. Journal of Research in Personality, 20, 460-473.

Ambady, A., Paik, S. K., Steele, J., Owen-Smith, A., \& Mitchell, J. P. (2003). Deflecting negative self-relevant stereotype activation: The effects of individuation. Journal of Experimental Social Psychology, 40, 401-408.

Ambady, A., Shih, M., Kim, A., \& Pittansky, T. L. (2001). Stereotype susceptibility in children: Effects of identity activation on quantitative performance. Psychological Science, 12(5), 385-390.

Aronson, J., Lustina, M. J., Good, C., \& Keough, K. (1999). When White men can't do math: Necessary and sufficient factors in stereotype threat. Journal of Experimental Social Psychology, 35, 29-46.

Aronson, J., \& Salinas, M. F. (1997). Stereotype threat, attributional ambiguity, and Latino under performance. Unpublished manuscript, University of Texas, Austin.

Bandura, A. (1994). Self-efficacy. In V. S. Ramachaudran (Ed.), Encyclopedia of human behavior (Vol. 4, pp. 71-81). New York: Academic Press. 
(Reprinted in H. Friedman [Ed.], Encyclopedia of mental health. San Diego: Academic Press, 1998).

Bandura, A. (1986). Social foundations of thought and action: A social cognitive theory. Englewood Cliffs, NJ: Prentice-Hall.

Bandura, A. (1977). Social Learning Theory. New York: General Learning Press

Bartlett, M. S. (1954). A note on the multiplying factors for various chi square approximations. Journal of the Royal Statistical Society, 16 (Series B), $296-298$.

Brown, R. P., \& Josephs, R. A. (1999). A burden of proof: Stereotype relevance and gender differences in math performance. Journal of Personality and Social Psychology, 76(2), 246-257.

Brown, R. P., \& Josephs, R. A. (2000). The importance of importance: The mathematics identification questionnaire. Unpublished manuscript, The University of Texas atAustin.

Cadinu, M., Maass, A., Frigerio, S., Impagliazzo, L., \& Latinotti, S. (2003).

Stereotype threat: The effect of expectancy on performance. European Journal of Social Psychology, 33, 267-285. 
Craik, F., \& Lockhart, R. (1972). Levels of processing: A framework for memory research. Journal of Verbal Learning and Verbal Behavior, 11, 671-684.

Croizet, J., \& Claire, T. (1998). Extending the concept of stereotype threat to social class: The intellectual underperformance of students from low socioeconomic backgrounds. Personality and Social Psychology Bulletin, $24,588-594$.

Educational Testing Services. (1994). GRE: Practicing to take the general test $\left(9^{\text {th }}\right.$ ed.). Princeton, NJ: Author.

Good, C., Aronson, J., \& Inzlicht, M. (2003). Improving adolescents' standardized test performance: an intervention to reduce the effects of stereotype threat. Journal of Applied Developmental Psychology, 24(6), 645-662.

Gresky, D. M., Ten Eyck, L. L., Lord, C. G., \& McIntyre, R. (n.d.). Effects of salient multiple identities on women's performance under mathematics stereotype threat. Unpublished manuscript, Texas Christian University and Amherst College.

Harvey, J. H., \& Weary, G. (1984). Current issues in attribution theory and research. Annual Review of Psychology, 35, 427-59. 
Herzig, A. (2004). Slaughtering this beautiful math: Graduate women choosing and leaving mathematics. Gender and Education, 16(3), 379-395.

Inzlicht, M., Aronson, J., Good, C., \& McKay, L. (2006). A particular resiliency to threatening environments. Journal of Experimental Social Psychology, 323-336.

Inzlicht, M., Aronson, J., \& McKay, L. (2006). Stigma as ego-depletion: How being the target of prejudice affects self-control. Psychological Science, $17,262-269$.

Inzlicht, M., \& Ben-Zeev, T. (2000). A threatening intellectual environment: Why females are susceptible to experiencing problem-solving deficits in the presence of males. Psychological Science, 11(5), 365-371.

Jacobs, B., Prentice-Dunn, S., \& Rogers, R. (1984). Understanding persistence: An interface of control theory and self-efficacy theory. Basic and Applied Social Psychology, 5(4), 333-347.

Johns, M., Schmader, T., \& Martens, A. (2005). Knowing is half the battle: Teaching stereotype threat as a means of improving women's math performance. Psychological Science, 16(3), 175-179. 
Lent, R. W., Brown, S. D., Brenner, B., Chopra, S. B., Davis, T., Talleyrand, R., \& Suthakaran, V. (2001). The role of contextual supports and barriers in the choice of math/science educational options: A test of social cognitive hypotheses. Journal of Counseling Psychology, 48, 474-483.

Levy, B. (1996). Improving memory in old age through implicit self-stereotyping. Journal of Personality and Social Psychology, 71, 1092-1107.

Lummis, M., \& Stevenson, H. W. (1990). Gender differences in beliefs and achievements: A cross-cultural study. Developmental Psychology, 26, 254-263.

Martens, A., Johns, M., Greenberg, J., \& Schimel, J. (2006). Combating stereotype threat: The effect of self-affirmation on women's intellectual performance. Journal of Experimental Social Psychology, 42(2), 236-243.

McAuley, E., Duncan, T. E., \& Russell, D. W. (1992). Measuring causal attributions: The revised causal dimension scale (CDS-II). Personality and Social Psychology Bulletin, 18(5), 566-573.

McAuley, E., Duncan, T. E., \& McElroy, M. (2001). Self-efficacy cognitions and causal attributions for children's motor performance: An exploratory investigation. The Journal of Genetic Psychology, 150(1), 65-73. 
McIntyre, R. B., Paulson, R. M., \& Lord, C. G. (2003). Alleviating women's mathematics stereotype threat through salience of group achievements. Journal of Experimental Social Psychology, 39, 83-90.

National Center for Education Statistics. (2004). Trends in educational equity for girls and women. Retrieved October 12, 2005, from http://nces.ed.gov/pubs2005/equity/.

National Science Foundation. (2000). Biennial report to the United States congress. Retrieved October 19,2005, from http://www.nsf.gov/pubs/2001/ceose2000rpt/congress 7.pdf

National Science Foundation. (2006). Division of science resources statistics, survey of earned doctorates, 1996-2003. Retrieved October 19, 2005, http://www.nsf.gov/statistics/wmpd/pdf/tabf-2.pdf

Nesbitt-Shelton, E. (2003). Faculty support and student retention. Journal of Nursing Education, 42(2), 68-76.

Nielson, I. L., \& Moore, K. A. (2003). Psychometric data on the mathematics self-efficacy scale. Educational and Psychological Measurement, 63, 128 138. 
Oswald, D. L., \& Harvey, R. D. (2001). Hostile environments, stereotype threat, and math performance among undergraduate women. Current Psychology, $19(4), 338-356$.

Pajares, F. (1996). Self-efficacy beliefs in academic settings. Review of Educational Research, 66(4), 543-578.

Pintrich, P. R., \& DeGroot, E. V. (1990). Motivational and self-regulated learning components of classroom academic performance. Journal of Educational Psychology, 82(1), 33-40.

Quinn, D. M., \& Spencer, S. J. (2001). The interference of stereotype threat with women's generation of mathematical problem-solving strategies. Journal of Social lssues, 57(l), 55-71.

Rivardo, M. G., Rhodes, M. E., \& Klein, B. (2008). Lack of stereotype threat at a liberal arts college. College Student Journal, 42, 832-41

Roccas, S., \& Brewer, M. B. (2002). Social identity complexity. Personality and Social Psychology Review, 6, 88-106. 
Sackett, P. R., Hardison, C. M., \& Cullen, M. J. (2004) On interpreting stereotype threat as accounting for African American-White differences on cognitive tests. American Psychologist, 59(1), 7-13.

Schunk, D. H., \& Gunn, T. P. (1986). Self-efficacy and skill development: Influence of task strategies and attributions. Journal of Educational Research, 79(4), 238-244.

Seymour, E. (1995). The loss of women from science, mathematics, and engineering undergraduate majors: An explanatory account. Science Education, 79(4), 437473.

Seymour, E., \& Hewitt, N. M. (1997). Talking about leaving: Why undergraduates leave the sciences. Boulder, $\mathrm{CO}$ : Westview.

Shelton, E. N. (2003). Faculty support and student retention. Journal of Nursing Education, 42(2), 68-82.

Shih, M., Pittansky, T. L., \& Ambady, N. (1999). Stereotype susceptibility: Identity salience and shifts in quantitative performance. Psychological Science, 10(1), 80-83. 
Spencer, S. J., Steele, C. M., \& Quinn, D. M. (1999). Stereotype threat and women's math performance. Journal of Experimental Social Psychology, $35,4-28$.

Steele, J., James, J., \& Barnett, R. (2002). Learning in a man's world: Examining the perspectives of undergraduate women in male-dominated academic areas. Psychology of Women Quarterly, 26(l), 46-50.

Steele, C. M. (1999). "Stereotype threat" and Black college students. The Atlantic Monthly, 284, 44-47, 50-54.

Steele, C. M. (1997). A threat in the air: How stereotypes shape the intellectual identities and performance of women and African-Americans. American Psychologist, 52(6), 613-629.

Steele, C. M., \& Aronson, J. (1995). Stereotype threat and the intellectual test performance of African Americans. Journal of Personality and Social Psychology, 69(5), 797-811.

Stone, J., Lynch, C. I., Sjomeling, M., \& Darley, J. M. (1999). Stereotype threat effects on Black and White athletic performance. Journal of Personality and Social Psychology, 77, 1213-1227. 
Storms M. D., \& McAul, K. D. (1976). Attribution processes and emotional exacerbation of dysfunctional behavior. In J. H. Harvey, W. J. Ickes, \& R. F. \& Kidd (Eds.), New directions in attribution research (pp. 143-164). Hillsdale, New Jersey: Lawrence Erlbaum.

Summers, L. (2005). Diversifying the science and engineering workforce: Women, underrepresented minorities, and their science \& engineering careers. Retrieved October 1, 2007, from

\section{http://www.president.haryard.edu/speeches/2005/nber.html}

Vogt, C. M., Hocevar, D., \& Hagedorn, C. S. (2007). A social cognitive construct validation: Determining women's and men's success in engineering. The Journal of Higher Education, 78(3), 337-364.

Weiner, B. (1985). An attribution theory of achievement motivation and emotion. Psychological Review, 92(4), 548-573.

Weiner, B. (1989). Human motivation. Hillsdale, New Jersey: Lawrence Erlbaum.

Wilson,. T. D., Damiani, M., \& Shelton, N. (2002). Improving the academic performance of college students with brief attributional interventions. In J. Aronson (Ed.), Improvement of academic achievement: Impact of psychological factors on education (pp. 89-107). San Diego, CA: Academic Press. 
Wilson, T. D., \& Linville, P. W. (1985). Improving the performance of college freshmen with attributional techniques. Journal of Personality and Social Psychology, 49, 287-293.

Zeldin, A. L., \& Pajares, F. (2000). Against the odds: Self-efficacy beliefs of women in mathematical, scientific, and technical careers. American Educational ResearchJournal, 37(1), 215-246.

Zimmerman, B. J., Bandura, A., \& Martinez-Pons, M. (1992). Self-motivation for academic attainment: The role of self-efficacy beliefs and personal goal setting. American Educational Research Journal, 29(3), 663-676. 